\title{
FE Modeling and Seismic Performance Evaluation of Hybrid SMA-Steel RC Beam-Column Joints
}

\author{
Mostafa Rezvanisharifa* \\ Mohammad Sadegh Ketabi ${ }^{\mathrm{a}}$ \\ a Civil Engineering Faculty, K. N. Toosi University of Technology, Tehran, Iran. E-mail: Rezvanisharif@kntu.ac.ir, \\ E-mail: msketabi@mail.kntu.ac.ir \\ *Corresponding author
}

http://dx.doi.org/10.1590/1679-78255272

\begin{abstract}
Severe permanent deformations of buildings during earthquakes have been found as one of the major causes of the instability and failure of structures. The application of superelastic Shape Memory Alloy rebars at the plastic hinge region of reinforced concrete beam-column joints (SESMA-BCJs) can eliminate the seismic residual deformations. Such self-centering structures can maintain their reusability even after severe earthquakes. This research proposes a simple - yet practical - technique for more accurate modeling of SESMA-BCJs using VecTor2 software. Both material and geometric nonlinearity were considered. Efficiency and versatility of the modeling approach were verified against a number of test results at both material and structural levels. According to the results, the adopted modeling approach can be reliably used for the prediction of the cyclic response of hybrid SESMA-BCJs under changing various design parameters which are beyond the scope of the experimental tests. Furthermore, using the calibrated model, a comprehensive seismic parametric study was conducted to investigate the influence of various design parameters on the seismic performance of SESMA-BCJs. Finally, a new Fe-based SESMA-BCJ with a lower amount of SESMA and higher seismic performance than NiTi-based BCJs was introduced and numerically investigated.
\end{abstract}

\section{Keywords}

nonlinear FE modeling; hybrid SMA-steel beam-column joint; shape memory alloy; self-centering; smart material

\section{INTRODUCTION}

Severe residual deformations of buildings and bridges during earthquakes have been found as one of the major causes of instability and failure of structures (Alam et al., 2007). Reuse of these structures is usually impossible or, if possible, requires repairing and strengthening with high costs. Therefore, "self-centering" structures with the ability to return to the initial position have been considered by some researchers. Self-centering along with the ability to dissipate the earthquake energy through energy dissipation devices are the main features of these structures. In self-centering reinforced concrete (RC) structures, such systems usually involve the post-tensioned reinforcement, complex steel detailing, and precast concrete segments. While the complexity of implementing such systems restricts their use in the construction industry (Oudah, 2015). As an alternative and simple technique toward construction of self-centering RC structures, superelastic Shape Memory Alloy (SESMA) can be used as the flexural reinforcement in the plastic hinge region of monolithic beam-column joints. These hybrid SMA-steel BCJs can potentially regain their original shape even after a severe earthquake (Alam et al., 2007).

Superelastic Shape Memory Alloys (SESMAs) can undergo large strains and return to their initial shape after the removal of stress (Jalaeefar and Asgarian, 2013). This novel material (SMA) has found increasing applications in engineering fields. An extensive review concerning the use of SMA in civil engineering structures has been presented by 
Janke et al. (2005), Song et al. (2006), and Ozbulut et al. (2011). Some of these studies have experimentally investigated the application of SMA as reinforcing bars in structural components of reinforced concrete structures. For example, Saiidi and Wang (2006) used SMA rebars in the plastic hinge region of RC Columns. These tests showed that SMA-RC columns were able to recover nearly all of the post-yield deformation, thus requiring minimal repair. Saiidi et al. (2007) explored the ability of NiTi (SESMA) to recover and reduce permanent deformations of concrete beams. Youssef et al. (2008) tested two large-scale beam-column joint subassemblies under reversed cyclic loading. These tests indicated that the hybrid SMA-BCJs were able to recover most of the permanent deformations. Thus, they would require a minimum amount of repair even after a strong earthquake. Saiidi et al. (2009) attempted to reduce permanent damages and deformations in RC bridge columns subjected to strong seismic loading using a combination of ECC and SMA bars in the plastic hinge zone of columns. Nehdi et al. (2010) experimentally investigated a SMA-FRP hybrid RC beam-column joint reinforced with superelastic Ni-Ti SMA bars at the plastic hinge region of the beam and FRP in the other regions of the beam and column. Abdulridha et al. (2013) carried out seven tests on simply supported flexure-critical concrete beams reinforced with either SMA bars in the critical region or conventional steel reinforcement. Also, they developed a preliminary constitutive model for superelastic SMA that was applicable to nonlinear finite element modeling. Oudah (2015) experimentally and numerically investigated the seismic performance of innovative self-centering concrete beamcolumn connections reinforced with SMA bars. While the plastic hinges were relocated by moving vertical slots away from the column face. Abdulridha and Palermo (2017) explored the seismic performance of hybrid SMA-steel RC shear wall. In other experimental investigation conducted on the RC shear walls, Cortés-Puentes and Palermo (2017) developed a self-centering device using SMA bars to improve the seismic performance of deficient squat shear walls. Oudah and ElHacha (2017) investigated the effectiveness of screw lock anchors for anchoring SESMA bars in reinforced concrete units.

There are other studies that have numerically investigated the application of SMA bars in RC members. For instance, Alam et al. (2008) studied the applicability of the existing rules to predict some of the seismic characteristics of SESMAsteel beam-column joints including width and spacing of concrete cracks and the length of the plastic hinge region. Roh and Reinhorn (2010) investigated the use of SESMA bars for improving the hysteretic performance of post-tensioned (PT) segmental bridge piers. Alam et al. (2012) estimated seismic over strength and ductility of concrete buildings reinforced with superelastic Shape Memory Alloy rebars. Other numerical works in this field can be found in the publications: (Wierschem and Andrawes, 2010), (Zafar and Andrawes, 2012), (Billah and Alam, 2012), (Tazarv and Saiidi, 2014), (Zafar and Andrawes, 2015).

According to the literature review, the number of studies investigating hybrid SMA-steel beam-column joints are very limited and detailed information about the seismic performance of these connections under changing different design parameters is not available now. On the other hand, various provisions and design guidelines need to be developed for establishing SMA as reinforcement in real RC structures. Therefore, more experimental and numerical investigations should be conducted in this field. Hence, the contribution of the present study may be summarized as follows:

1. Modifying the constitutive model of SMA in the numerical model of VecTor2 for more accurately reproducing the cyclic response of hybrid SMA-steel beam-column joints.

2. Evaluating the accuracy and applicability of the adopted modeling approach against a number of test results at both the material and structural levels.

3. Conducting a comprehensive seismic parametric study that investigates the effect of different design parameters on the seismic performance of hybrid SMA-BCJs.

4. Proposing an approach for reducing the amount of required SESMA and enhancing the seismic performance of hybrid SMA-steel beam-column joints, and investigating its efficacy through a numerical study.

\section{NONLINEAR FE MODELING}

In the present research, 2D FEM software VecTor2 (Ver. 3.5) was used to assess the seismic performance of selfcentering hybrid SESMA BCJs. This software is a nonlinear finite element program which can analyze two-dimensional reinforced concrete membrane structures. The solution algorithm of this software is based on a total-load secantstiffness formulation, while employing an incremental and iterative procedure, providing a robust and stable nonlinear solution with good convergence characteristics (Wong et al. 2013). VecTor2 utilizes a smeared, rotating-crack formulation for the cracked concrete modeling in accordance with the Disturbed Stress Field Model (Vecchio 2000) as an extension of the Modified Compression Field Theory (Vecchio and Collins 1986). In this program, the cracked concrete is considered as an orthotropic material. 


\subsection{Finite element modeling and validation of numerical models}

Validation and calibration of numerical models are necessary to achieve realistic results. In the present study, the numerical predictions were validated against a number of experimental results presented in previous studies (Abdulridha et al. 2013; Omori et al. 2011; Oudah 2015; Tanaka et al. 2010; Youssef et al. 2008). These experiments include two sets of tests. The first set focuses on SESMA cyclic stress-strain behavior at the material level. While the second set includes the cyclic response of conventional (BCJs with only steel rebars) and hybrid beam-column joint assemblages (with both steel and SMA rebars). The second set was employed to show the accuracy, effectiveness, and applicability of the adopted FE modeling approach at the structural level.

\subsubsection{FE meshing}

In the finite element modeling, accurate meshing is an important factor in achieving more accurate results. Therefore, a mesh sensitivity analysis should be performed to select an adequate mesh size and to approximately avoid mesh-dependency (Abdelwahed et al. 2018; Najafgholipour et al. 2017; Sanabria Diaz et al. 2018). Indeed, it is to be investigated that the mesh size dependency does not significantly affect the overall response of the numerical models.

In the present study, at first, for each BCJ, a preliminary numerical model was made using the simple rectangular elements and a relatively coarse mesh in the range of about $80-100 \mathrm{~mm}$. After selecting the proper constitutive models and defining their parameters, providing a relatively close agreement between the numerical predictions and experimental results, the number of elements was increased by applying progressively finer meshes until the numerical prediction stabilized and well matched with the experimental response. Figure 1 shows the effects of the element (mesh) size and type on the load-displacement response of the numerical model of JBC2 (a calibrated model which will be used for parametric study in sec. 3).

It was observed that employing a mesh size in the range of about $25-35 \mathrm{~mm}$, with an aspect ratio lower than 1.5 , at the critical zones where higher levels of yielding, bond-slip, and concrete damage are expected (particularly at the joint panel and the plastic hinge region), can provide sufficient accuracy. A similar suggestion could be found in the related studies (Ronagh and Baji 2014; Sagbas et al. 2011; Del Vecchio et al. 2015, 2016). In the other regions (outside the critical zones), the mesh size can be consistently increased (for example, up to $60 \mathrm{~mm}$ for JBC2). Figure 1a shows the superiority of the mesh size in the range of 25-60 mm as compared to larger sizes.

In order to study the effect of the element type on numerical responses, the concrete zones of the $\mathrm{BCJ}$ s were also modeled using quadrilateral elements (higher-order than rectangular). The elapsed time of the analysis for the quadrilateral elements was more than that for the rectangular elements. However, no significant differences were observed in the analysis results (Figure 1b), and hence the rectangular elements were employed for the numerical modeling.
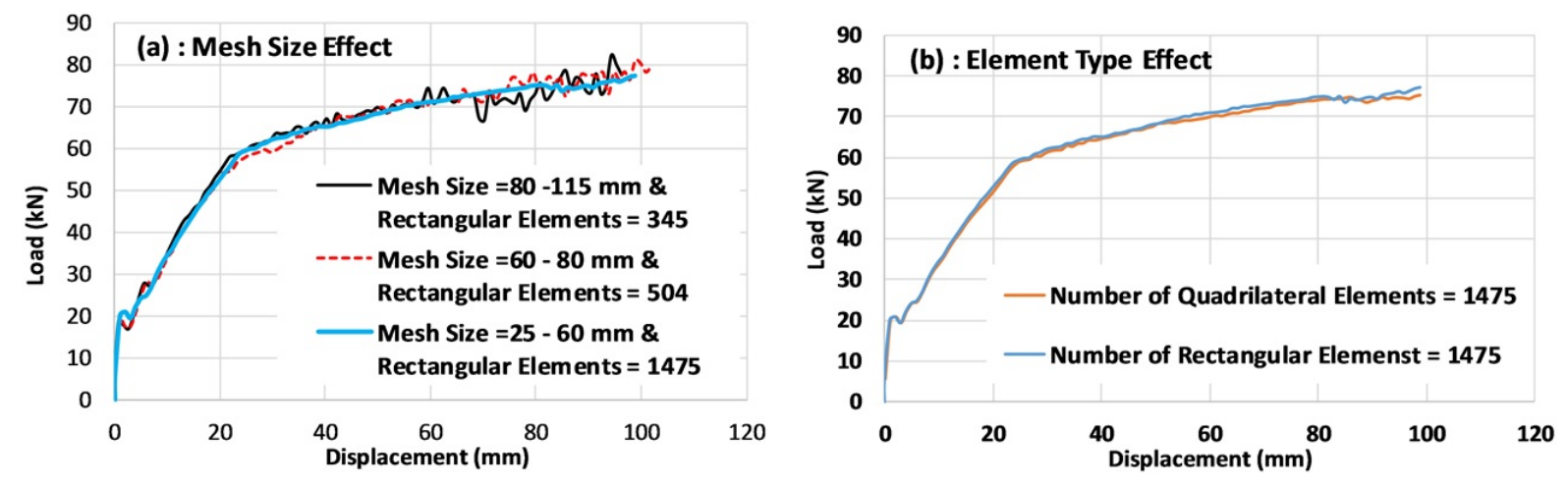

Figure 1: The effects of the element (mesh) size and type on the load-displacement response of JBC2

\subsubsection{Concrete modeling}

The concrete regions of the beam-column joint subassemblies were modeled using standard 2D plane stress rectangular elements (i.e., $8 \mathrm{DOF}$ ). The pre-peak and post-peak compression stress-strain behaviors of the concrete were modeled using Hoshikuma et al. model (Hoshikuma et al., 1997). In this model peak compressive stress $f_{p}$ and corresponding strain $\varepsilon_{p}$ depend upon the amount of hoop reinforcement. On the analysis process, these parameters are modified by a compression softening model (reducing the compressive strength and stiffness of cracked concrete due to coexisting transverse cracking and tensile straining) and a strength enhancement model (allowing for the confinement 
effects). In the present study, for incorporating the compression softening effects, the "Vecchio 1992-A(e1/e2-Form)" model (Wong et al. 2013) (which is based on the model of Vecchio and Collins (1986)) and for considering the strength enhancement effects, "Kupfer/Richart" model (Wong et al. 2013) (which is an adapted and combined version of the models proposed by Kupfer et al. (1969) and Richart et al. (1928)) were used. Lateral expansion (concrete dilation) effects were modeled using "Variable Montoya with Limit" model (Montoya et al. 2006), incorporating the concrete dilation as a function of the concrete compressive strength and the lateral pressure ratio.

In tension, the "Lee 2011 (w/ Post Yield)" model (Lee et al., 2011) and the "Bilinear" model (Comité EuroInternational du Béton 1993) were employed to account for the tension stiffening and tension softening effects, respectively. The Mohr-Coulomb criterion (a stress-based formulation (Wong et al. 2013)) was used as the cracking criterion. The cracking criterion calculates the concrete cracking strength $f_{c r}$, which is not generally equal to the input value of the concrete tensile strength $f_{t}$, under the effects of stress states.

For calculating shear stress on concrete cracks, the "Advanced Lee model" (Wong et al. 2013) was used. The formulation of this model is based on the "Disturbed Stress Field Model" (DSFM) (Vecchio 2000) and the "Modified Compression Field Theory" (MCFT) (Vecchio and Collins 1986), while employing different convergence criteria (bi-section criteria). Shear slip along the surfaces of cracks was calculated according to the "Vecchio-Lai (cyclic)" model (Vecchio and Lai 2004).

To simulate the hysteretic behavior of concrete, the "Palermo - Nonlinear with Cyclic Decay" model (Palermo and Vecchio, 2003) was utilized (Figure 2a). This model accounts for the damage mechanisms in the reloading, partial loading, and unloading phases. The concrete constitutive models used are summarized in Table 1.

\subsubsection{Reinforcement modeling}

In the present study, there are two types of reinforcement materials: steel and SESMA rebars. In order to model reinforcement, either discrete or smeared reinforcement element can be utilized. Both transverse (shear) and longitudinal (flexural) reinforcements were modeled using discrete two-node truss elements. Smeared reinforcement was used to model the out-of-plane confinement effects provided by the hoops or closed stirrups and ties. The couplers were modeled by a truss bar with the equivalent cross-sectional area, length, and material properties. "Seckin model with Bauschinger effect" (Seckin, 1982) was employed for modeling the hysteretic response of steel reinforcement (Figure 2b). The "SMA2" was utilized to model the superelastic behavior of the Shape Memory Alloy reinforcement bars (see Figure 2c). The SMA2 is a model from the VecTor2 which incorporates strain hardening as well as small strain offset (Wong et al., 2013). For more exact modeling of SESMA behavior, this model was modified by the parallel use of SMA2 and linear elastic behavior (see Sec. 2.2). Buckling (based on "Asazu model" (Asazu et al., 2001)) and dowel action (based on "Tassios model" (Tassios and Vintzēleou, 1987)) of steel and SESMA rebars were also considered.

Table 1. Material behavior models utilized in the modeling of concrete

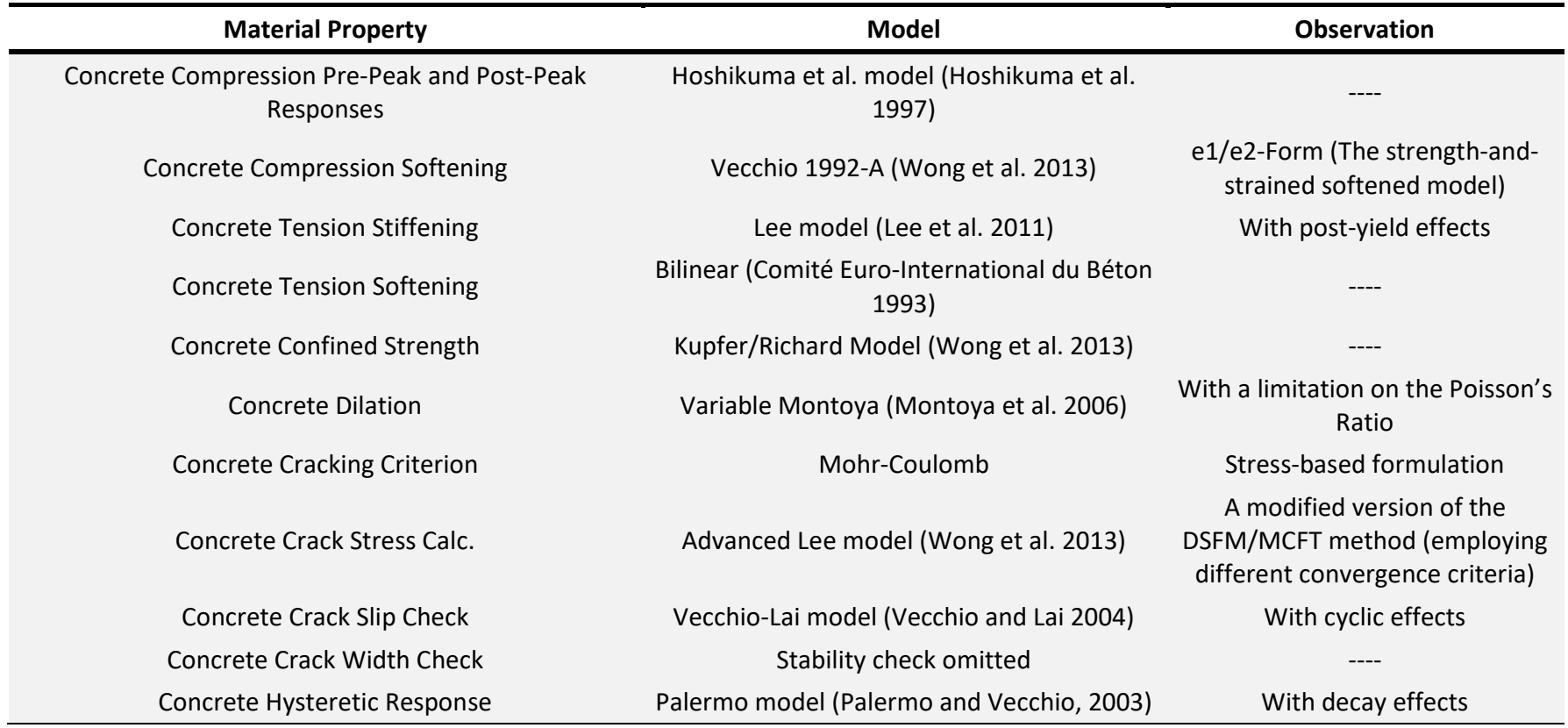



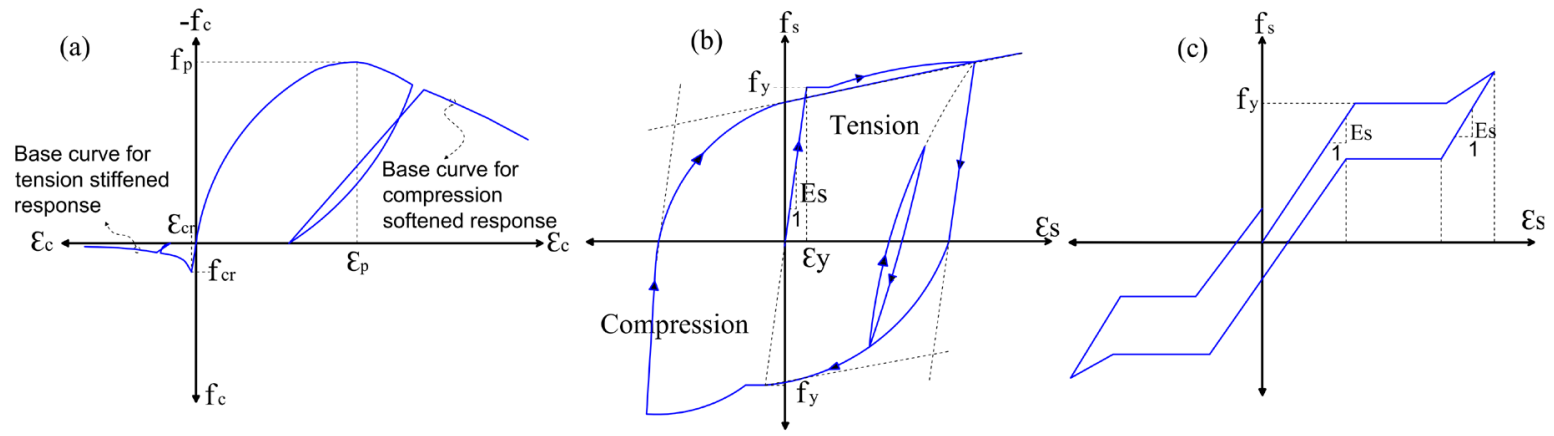

Figure 2: Hysteretic behavior models: (a) concrete in tension and compression, (b) steel reinforcement, and (c) SESMA rebar (Wong et al., 2013)

\subsubsection{Bond stress-slip modeling}

The cyclic response of beam-column joint subassemblies is significantly affected by the bond stress-slip behavior of the beam longitudinal reinforcement (Azimi et al. 2015; Beydokhty and Shariatmadar 2016). In order to model the imperfect bonding condition between the reinforcement and concrete, the "Link" elements were used (as interface elements). For both of the steel and SESMA reinforcing bars, the reversed cyclic model developed by Eligehausen et al. (1982) was assigned to the interface (Link) elements for simulating the hysteretic behavior of the bond material. Since the hysteretic characteristic parameters of the bond stress-slip behavior mainly depend on the concrete strength and the surface roughness of the rebars (Verderame et al. 2009), the characteristic parameters associated with the envelope curve of the hysteretic (cyclic) model were determined by two different methods for deformed steel rebars and SESMA bars (sand coated or smooth). For the steel reinforcement, "Embedded Deformed Rebars" option available in the software VecTor2 was utilized, and appropriate values for the confinement pressure factor $\beta$ and concrete cover were in putted. More detailed information concerning this factor $(\beta)$ can be found in the corresponding ref. (Wong et al. 2013). For SMA reinforcing bars, "Embedded Bars-Custom Input" option was chosen. In this method, the bond stress-slip relationship is defined by a series of reference bond stresses and slips (three reference points). These reference points were determined according to the bond stress-slip relationship of SESMA bars, proposed by Billah and Alam (2016). This relationship and the reference points used (for sand-coated SESMA bars) are shown in Figure 3. The average maximum bond strength in this relationship was calculated according to the following equations.

$\tau_{\max }=k_{r} \times\left(0.9-0.004 d_{b}-0.0025 l_{d}+0.015 \frac{c}{d_{b}}\right) \times \sqrt{f_{c}^{\prime}}$

$k_{r}=0.17 \alpha^{2}-1.92 \alpha+6.5$

$\alpha=(2 /$ sand sizein $m m)$

where $\tau_{\max }$ is the average maximum bond strength in $\mathrm{MPa}, f_{c}^{\prime}$ is the concrete compressive strength in $\mathrm{MPa}, \mathrm{c}$ is the concrete cover in $\mathrm{mm}, d_{b}$ is the bar diameter in $\mathrm{mm}, l_{d}$ is the embedment length in $\mathrm{mm}, \alpha$ is the sand size coefficient, and $k_{r}$ is the surface roughness factor which is 1 for smooth rebar. For sand coated rebars, $k_{r}$ can be calculated by using Eq. 2 .

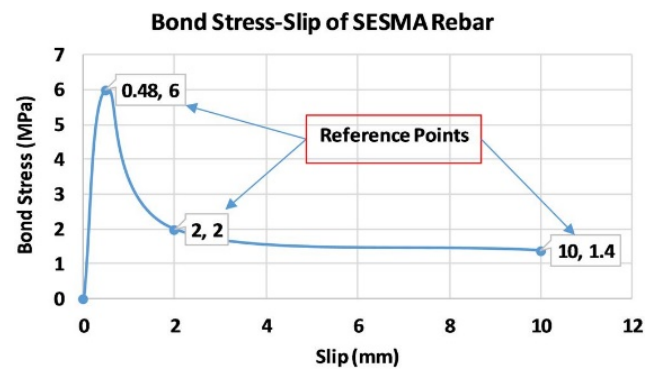

Figure 3: The user-defined bond stress-slip envelope curve for sand-coated SESMA rebars 


\subsection{Finite element modeling of the cyclic behavior of SESMA bars at the material level using VecTor2}

In the present study, the superelastic behavior of SESMA bars was modeled by a modified SMA model. This model consists of parallel use of a linear elastic approach added by the SMA2 model available in VecTor2 (see Figure 4). To investigate the accuracy of the adopted approach at the material level, the cyclic stress-strain behavior of four different types of SESMA samples (bars) tested by other authors (see Table 2) was numerically reproduced. Table 2 summarizes the mechanical properties of these SESMA bars, extracted from experimental tests. The results of numerical modeling are shown in Figure 5 and Figure 6.

Figure 5 a illustrates the cyclic stress-strain behavior of Ni55Ti45 specimens (bars) tested by Youssef et al. (2008). At first, the cyclic response of these SESMA bars was simulated by "SMA2" behavior model adopted by VecTor2 and is illustrated in Figure 5b. The SMA2 model was not of sufficient accuracy in reproducing the unloading path and capturing lower plateau stress at the material level. Indeed, in this model, the unloading path (from Martensite to Austenite phase) is modeled by a constant function instead of a linear function. Therefore, in the current study, the parallel use of the linear elastic behavior and "SMA2" model was employed to address this shortcoming. The stress-strain curve of Ni55Ti45 which was modeled by "Modified SMA2" (the parallel behavior model) is shown in Figure 5c.

To show the robustness of the adopted approach (i.e., the modification of SMA2 model), the numerical prediction of the stress-strain behavior of three other SESMA bars obtained by using the "modified SMA2" model is presented in Figure 6. The comparison of the experimental and numerical results shows that the adopted approach has more reasonable results. Therefore, this approach was used for the FE modeling of the cyclic response of hybrid SESMA-steel beam-column joints at the structural level.

Table 2: Mechanical characteristic of four SESMA Samples used in the numerical investigation

\begin{tabular}{ccccc}
\hline SESMA & FeMnAINi & FeNCATB & Ni56-Ti44 & Ni55-Ti45 \\
\hline$\sigma_{S}^{A M}(\mathrm{Mpa})^{1}$ & 320 & 750 & 415 & 401 \\
$\sigma_{f}^{A M}(\mathrm{Mpa})^{2}$ & 442.5 & 1200 & 540 & 510 \\
$\sigma_{S}^{M A}(\mathrm{Mpa})^{3}$ & 210.8 & 300 & 170 & 370 \\
$\sigma_{f}^{M A}(\mathrm{Mpa})^{4}$ & 122 & 200 & 120 & 130 \\
$\mathrm{E}(\mathrm{GPa})^{5}$ & 98.4 & 46.9 & 60 & 62.5 \\
$\varepsilon_{l}(\%)^{6}$ & 6.13 & 13.5 & 8 & 6 \\
$R e f f$. & Omori et al. (2011) & Tanaka et al. (2010) & Abdulridha et al. (2013) & Youssef et al. (2008) \\
\hline
\end{tabular}

${ }^{1} \sigma_{S}^{A M}$ : Austenite-to-Martensite starting stress, ${ }^{2} \sigma_{f}^{A M}$ : Austenite-to-Martensite finishing stress, ${ }^{3} \sigma_{S}^{M A}$ : Martensite-to-Austenite starting stress,

${ }^{4} \sigma_{f}^{M A}:$ Martensite-to-Austenite finishing stress, ${ }^{5} \mathrm{E}$ : Young's modulus, ${ }^{6} \varepsilon_{l}:$ Superelastic strain.
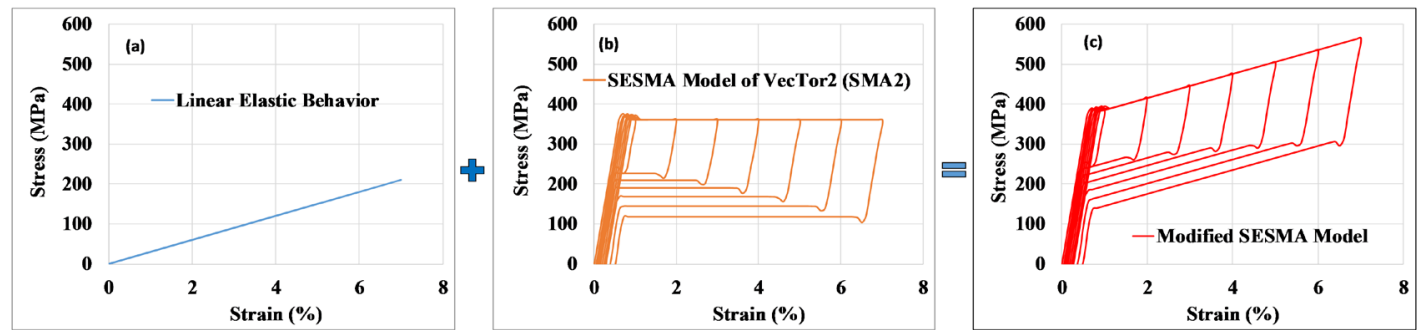

$\varepsilon_{a}=\varepsilon_{b}=\varepsilon_{c}, \sigma_{a}+\sigma_{b}=\sigma_{c} \Rightarrow \varepsilon *\left(E_{a}+E_{b}\right)=\varepsilon * E_{c} \Rightarrow E_{a}+E_{b}=E_{c}$

Figure 4: The method used for modifying SESMA model of VecTor2 

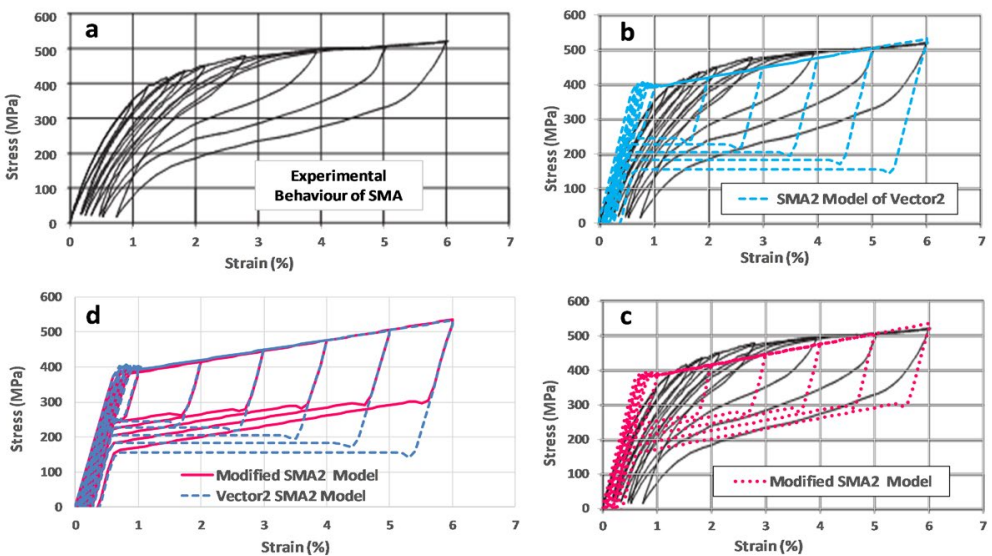

Figure 5: Experimental and numerical stress-strain curves of Ni55-Ti45: (a) experimental (Youssef et al. 2008), (b) numerical modeling by using the "SMA2" material model of Vec2, (c) numerical modeling by using the "Modified SMA2" material model, and (d) the comparison of cases $b$ and $c$.
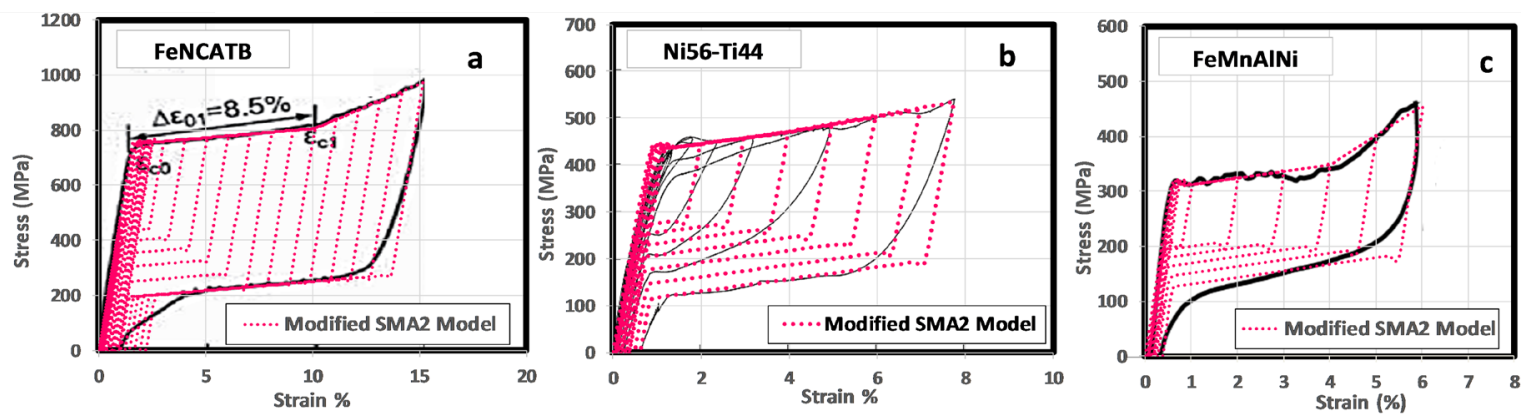

Figure 6: Comparison between experimental (see Table 2) and numerical stress-strain curves of three different types of SESMAs,

(a) FeNCATB SESMA, (b) Ni56-Ti44 SESMA, (c) FeMnAINi SESMA

\subsection{Finite element modeling of RC beam-column joints JBC1 and JBC2 (structural level)}

In this part of the research, the cyclic response of two RC beam-column joint assemblages tested by Youssef et al. (2008) was numerically reproduced. These RC BCJs (JBC1 and JBC2) were tested under reversed cyclic loading applied at the beam tip. Also, a constant axial force of $350 \mathrm{kN}$ was applied at the top cross-sectional area of the column representing gravity loads. The lateral load history consisted of two phases. It initiated with a load-controlled phase followed by a displacement-controlled phase. After yielding, displacement-controlled loading was applied in the form of incremental multiplies of the yield displacement. For each drift ratio, the test specimen was subjected to two complete cycles. The loading was terminated at a story drift of $7.9 \%$, which was more than double the collapse limit. The configuration and reinforcing details of JBC1 and JBC2 are illustrated in Figure 7. Detailed information about these tests can be found in the corresponding reference (Youssef et al. 2008). In the numerical models, the lateral reversed cyclic loading was applied at the nodes of the beam tip at a distance of $1630 \mathrm{~mm}$ from the column; and constant axial force was applied on the top nodes of the column. The location of the lateral and axial loads are shown in Figure 7. It should be noted that no significant difference was found between the results when applying the loads on either a single node or a number of nodes. However, distributing the load on a number of nodes can reduce stress concentration problems. 


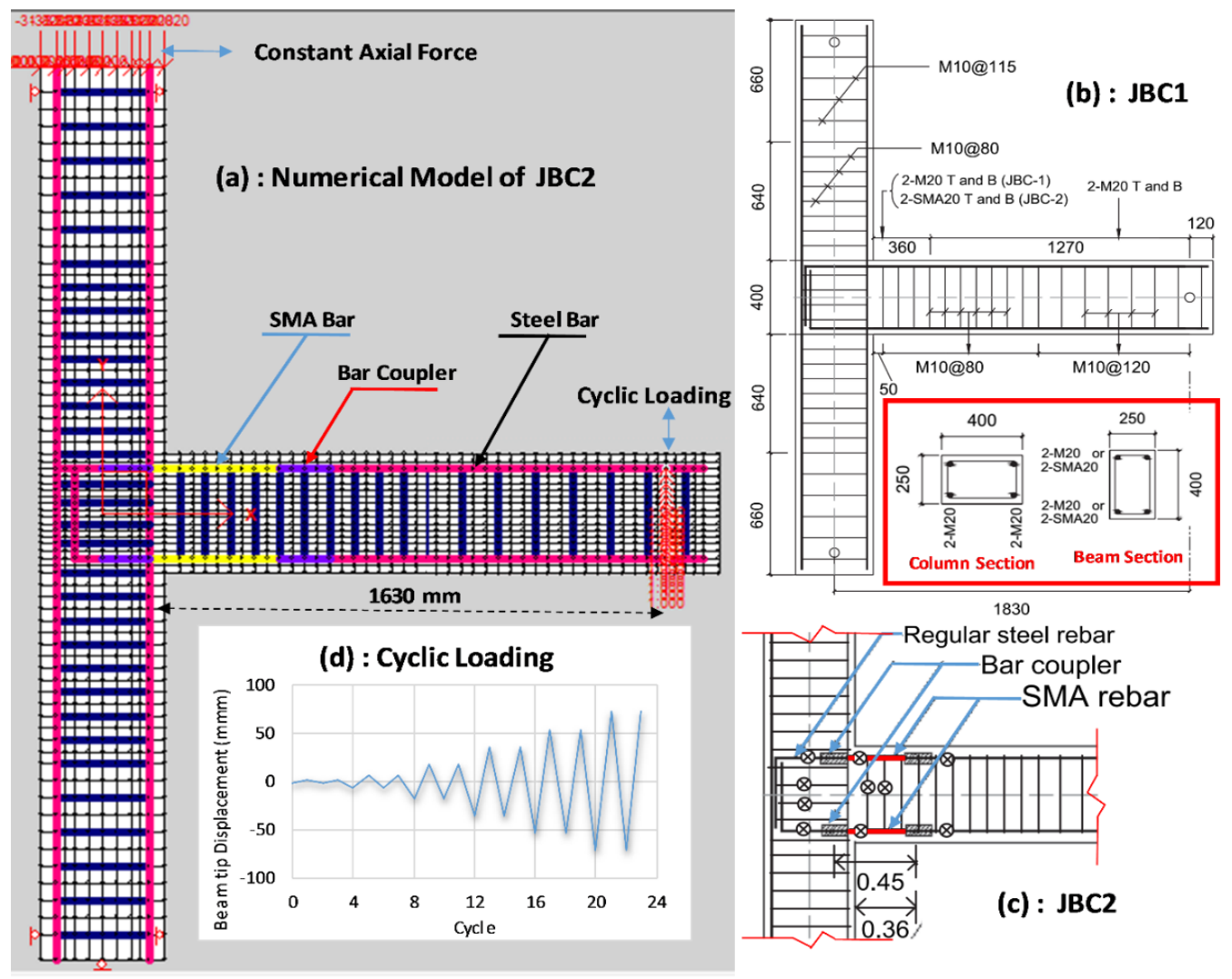

Figure 7: Typical FE model of JBC2 in VecTor2(a), details of specimens JBC1(b) and JBC2(c) (Youssef et al. 2008), and cyclic loading protocol(d)

JBC1 and JBC2 are similar in terms of configuration and reinforcing details except for the plastic hinge regions. JBC1 is a conventional beam-column joint with steel rebars at all regions of the specimen, whereas JBC2 is a hybrid beamcolumn joint with SESMA rebars at the plastic hinge zone of the beam, and steel rebars at other places of the specimen. Screw-lock mechanical couplers have been used to couple the $20 \mathrm{~mm}$ diameter SMA to the $20 \mathrm{M}$ deformed steel bars at the plastic hinge region.

The comparison between the test results and numerical predictions of JBC1 and JBC2 are shown in Figure 8 and Figure 9 and are summarized in Tables 3 and 4. As can be seen, the experimental results and numerical predictions are in a good agreement in terms of stiffness, yield and ultimate strengths, hysteresis energy dissipation, cracking pattern, failure mode, ductility, and displacement recovery. It can be concluded that the "Modified SMA2" model can satisfactorily simulate the cyclic behavior of SESMA at both the material and structural levels.

\subsection{Finite element modeling of RC beam-column joints SSB-S-1, DSB-S-1, SSB-P-1, and DSB-P-1}

In order to intensify the accuracy of the adopted modeling approach, the cyclic behavior of four other RC BCJs tested by Oudah (2015) was also reproduced. This set of tests include two conventional (with only steel rebars) and two hybrid SMA-steel BCJS, designated SSB-S-1, DSB-S-1, SSB-P-1, and DSB-P-1, respectively. Notice that "SSB" and "DSB" are acronyms for "Single Slotted Beam" (see Figure 10a and c) and "Double Slotted Beam" (see Figure 10b and d) respectively. Implementation detail, loading history, and material specifications have been considered the same as those of the tested specimens and can be found in the corresponding reference (Oudah 2015). The reinforcement details of the specimens and their typical numerical models are illustrated in Figure 10 (in which the applied loads are shown schematically). The comparison between the numerical predictions and experimental results in terms of load-displacement relationship and hysteresis energy dissipation is presented in Figure 11 and Figure 12, respectively. Furthermore, the quantitative comparison of numerical to experimental results is also given in Tables 3 and 4 . As can be seen, numerical results are in compliance with experimental findings. 


\section{NUMERICAL PARAMETRIC STUDY}

A numerical parametric study was conducted in order to study the seismic behavior of SMA. The numerical model calibrated based on the test results of specimen JBC2 was used as a basic model. The parameters to be varied are as follows:

- Mechanical properties of SESMA

- Concrete compressive strength

- Beam reinforcement ratio

\subsection{Influence of mechanical properties of SESMA}

In the following, the effects of mechanical properties of SESMA rebars (see Figure 13) on the seismic behavior of hybrid SMA-steel beam-column subassemblies were investigated. The parameters K1 (austenite modulus), K2 (post-yield stiffness), K3 (an alternative for studying the effect of the lower plateau stress factor ( $\beta$ )), and Fy (austenite yield strength) were changed and the results may be summarized as follows:

The effect of the austenite yield strength (Fy) on the seismic behavior of JBC2 was studied by changing the value of yield strength while the values of K1, K2, and K3 remained constant. As illustrated in Figure 14, with increasing the yield strength from 300 to $500 \mathrm{MPa}$, the load-bearing capacity increased by approximately $40 \%$ while energy dissipation decreased by approximately $16 \%$. Fy can affect the load-displacement relationship at displacements exceeding $20 \mathrm{~mm}$.

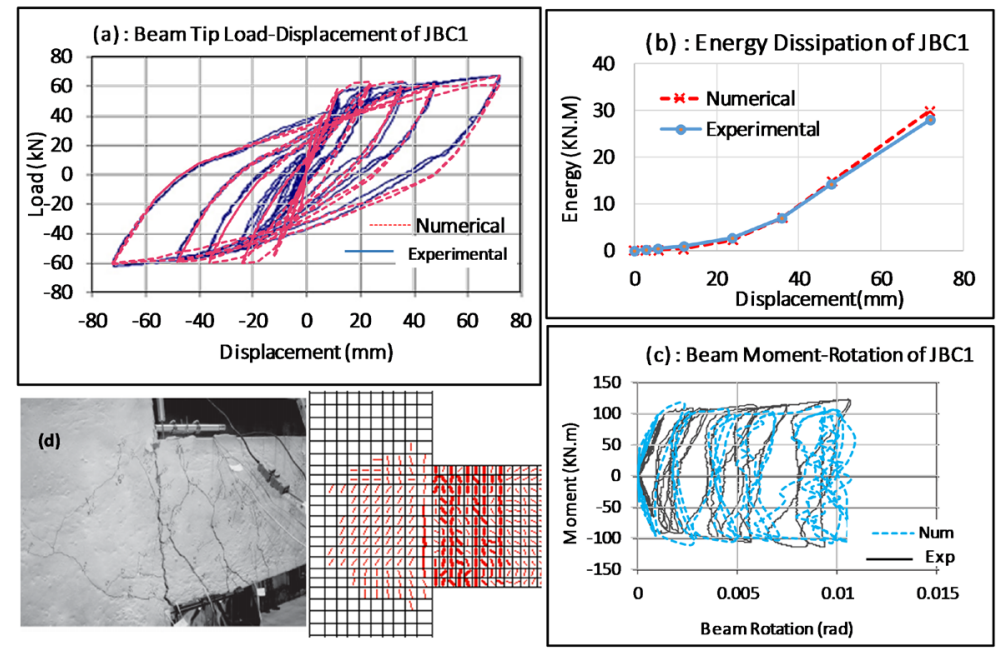

Figure 8: Comparison between the numerical predictions and experimental results (Youssef et al. 2008) of JBC1. (a) beam tip load-displacement, (b) energy dissipation, (c) beam moment-rotation, (d) cracking pattern
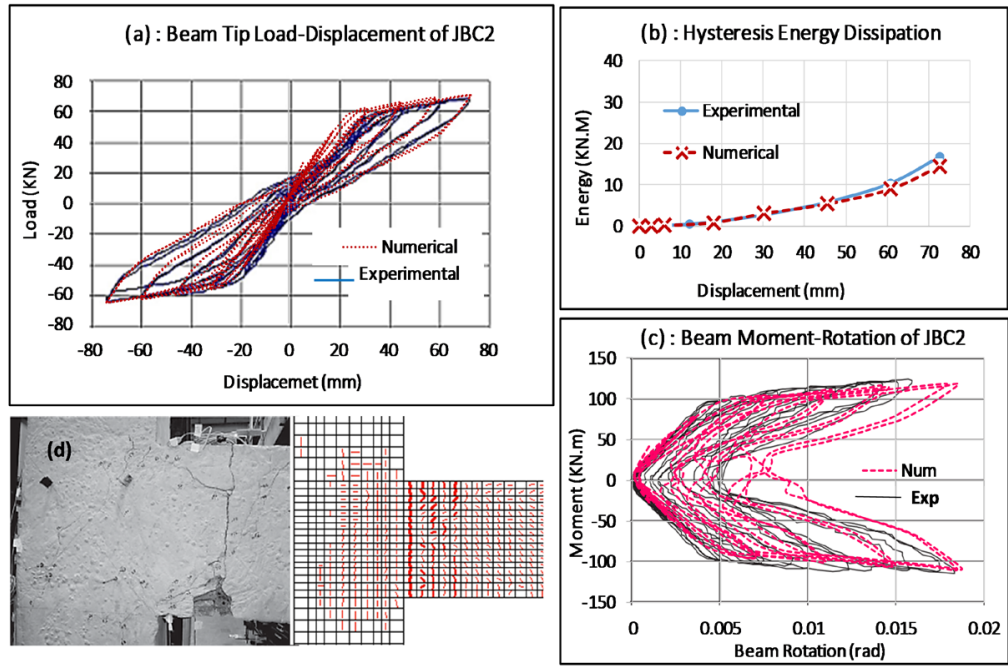

Figure 9: Comparison between the numerical predictions and experimental results (Youssef et al. 2008) of JBC2. (a) beam tip load-displacement, (b) energy dissipation, (c) beam moment-rotation, (d) cracking pattern 
To explore the effect of K1 (austenite modulus) on the seismic behavior of JBC2 (see Figure 15), Fy, K2, and K3 were assumed constant and K1 was altered between 30GPa to 70GPa. The initial stiffness and energy dissipation of JBC2 increased with increasing K1. The Change in K1 had a negligible effect on the load bearing capacity. K1 altered loaddisplacement curves only in a displacement range of 0 to $40 \mathrm{~mm}$.
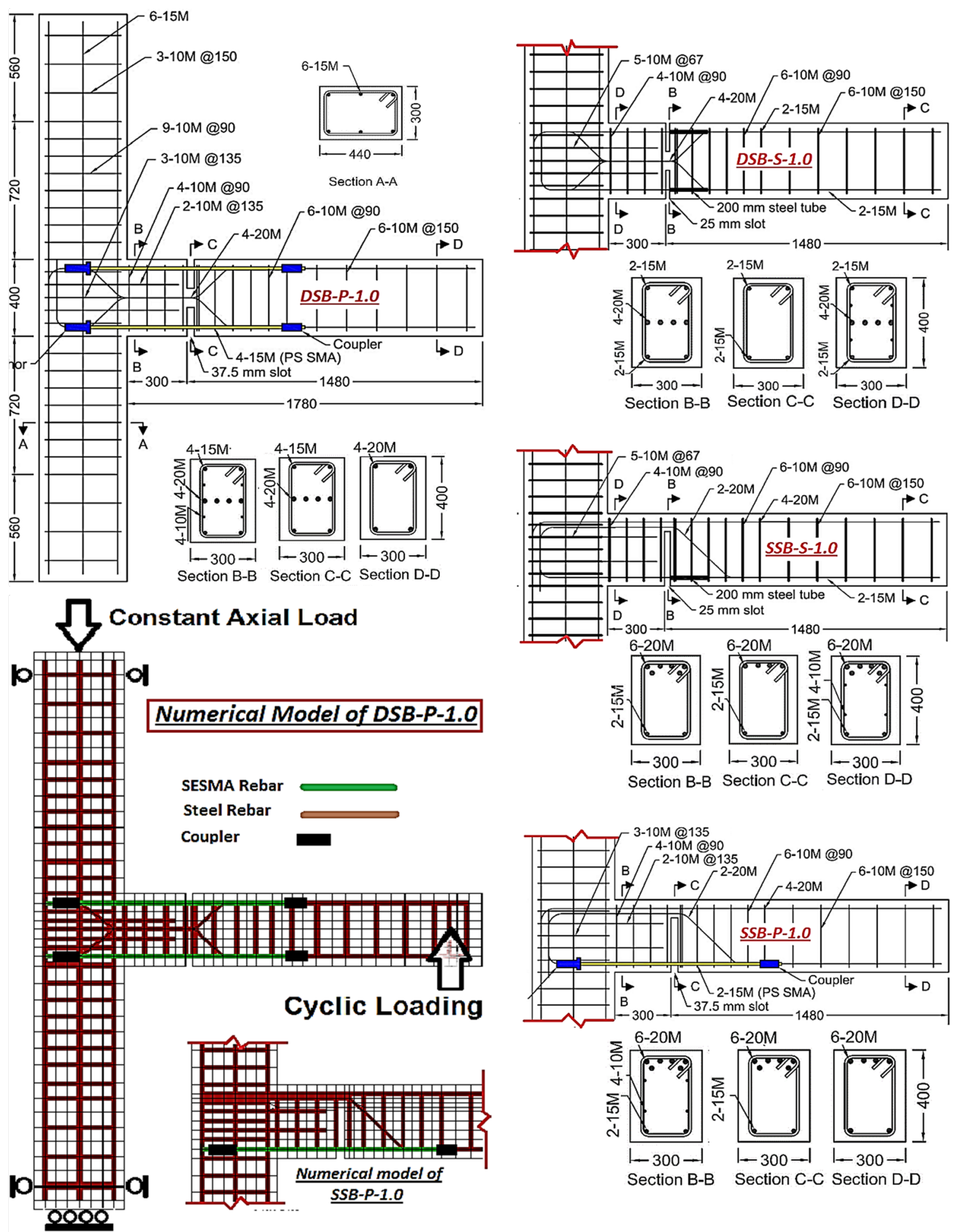

Figure 10: Details of test samples: DSB-P-1.0 (a), DSB-S-1.0(b), SSB-S-1.0(c), and SSB-P-1.0 (d) (Oudah 2015) and typical finite element modeling of DSB-P-1.0 and SSB-P-1.0 
Table 3: Comparison of predicted (Vec2) and measured (EXP) responses for positive loading direction

\begin{tabular}{|c|c|c|c|c|c|c|c|c|c|c|}
\hline \multirow{2}{*}{$\begin{array}{c}\text { Specimen } \\
\text { (Type of Reinforcement) }\end{array}$} & \multirow{2}{*}{ Result } & \multicolumn{2}{|c|}{$\begin{array}{l}\text { Yielding } \\
\text { Strength }\end{array}$} & \multicolumn{2}{|c|}{$\begin{array}{l}\text { Maximum } \\
\text { Strength }\end{array}$} & \multicolumn{2}{|c|}{$\begin{array}{l}\text { Ultimate } \\
\text { strength }\end{array}$} & \multirow{2}{*}{$\begin{array}{l}\text { Energy } \\
\text { (kN.m) }\end{array}$} & \multirow{2}{*}{$\frac{E_{V e c 2}}{E_{E X P}}$} & \multirow{2}{*}{$\frac{\mu_{V c e 2}}{\mu_{E X P}}$} \\
\hline & & $\begin{array}{l}\mathrm{Py} \\
(\mathrm{kN})\end{array}$ & $\begin{array}{c}\delta y \\
(\mathrm{~mm})\end{array}$ & $\begin{array}{l}P \max \\
(\mathrm{kN})\end{array}$ & $\begin{array}{l}\delta \max \\
(\mathrm{mm})\end{array}$ & $\begin{array}{l}\mathrm{Pu} \\
(\mathrm{kN})\end{array}$ & $\begin{array}{c}\delta u \\
(\mathrm{~mm})\end{array}$ & & & \\
\hline \multirow[t]{2}{*}{ JBC1 (Steel) } & EXP & - & - & 66.5 & 72 & 66.5 & 72 & 26.7 & 1.12 & - \\
\hline & Vec2 & 55.6 & 12 & 66.2 & 72 & 66.2 & 72 & 29.8 & & \\
\hline \multirow[t]{2}{*}{ JBC2 (SMA and Steel) } & EXP & 32.7 & 18 & 68.1 & 72 & 68.1 & 72 & 16.3 & 0.9 & 1.02 \\
\hline & Vec2 & 47 & 18.3 & 71 & 72 & 71 & 72 & 14.9 & & \\
\hline \multirow[t]{2}{*}{ SSB-S-1.0 (Steel) } & EXP & 40 & 11 & 67 & 55 & 67 & 55 & 59 & 1.13 & 0.91 \\
\hline & Vec2 & 44 & 10 & 66.7 & 55 & 66.7 & 55 & 67 & & \\
\hline \multirow[t]{2}{*}{ DSB-S-1.0 (Steel) } & EXP & 41 & 14 & 68 & 85 & 68 & 85 & 171.7 & 0.97 & 0.86 \\
\hline & Vec2 & 38.2 & 12 & 64.4 & 70 & 58.5 & 85 & 166 & & \\
\hline \multirow[t]{2}{*}{ SSB-P-1.0 (SMA and Steel) } & EXP & 44 & 32 & 44 & 75 & 44 & 75 & 26 & 0.81 & 1.09 \\
\hline & Vec2 & 43 & 35 & 45.8 & 75 & 45.8 & 75 & 21 & & \\
\hline \multirow[t]{2}{*}{ DSB-P-1.0 (SMA and Steel) } & EXP & 44 & 39 & 56 & 120 & 56 & 120 & 51.2 & 0.79 & $1 \bullet$ \\
\hline & Vec2 & 44.5 & 39 & 56.2 & 120 & 56.2 & 120 & 40.4 & & \\
\hline
\end{tabular}

Table 4: Comparison of predicted (Vec2) and measured (EXP) responses for negative loading direction

\begin{tabular}{|c|c|c|c|c|c|c|c|c|c|c|}
\hline \multirow{2}{*}{$\begin{array}{c}\text { Specimen } \\
\text { (Type of Reinforcement) }\end{array}$} & \multirow{2}{*}{ Result } & \multicolumn{2}{|c|}{$\begin{array}{l}\text { Yielding } \\
\text { Strength }\end{array}$} & \multicolumn{2}{|c|}{$\begin{array}{l}\text { Maximum } \\
\text { Strength }\end{array}$} & \multicolumn{2}{|c|}{$\begin{array}{l}\text { Ultimate } \\
\text { strength }\end{array}$} & \multirow{2}{*}{$\begin{array}{l}\text { Energy } \\
\text { (kN.m) }\end{array}$} & \multirow{2}{*}{$\frac{E_{V e c 2}}{E_{E X P}}$} & \multirow{2}{*}{$\frac{\mu_{V c e 2}}{\mu_{E X P}}$} \\
\hline & & $\begin{array}{l}\text { Py } \\
\text { (kN) }\end{array}$ & $\begin{array}{c}\delta y \\
(\mathrm{~mm})\end{array}$ & $\begin{array}{l}\text { Pmax } \\
\text { (kN) }\end{array}$ & $\begin{array}{l}\delta \mathrm{max} \\
(\mathrm{mm})\end{array}$ & $\begin{array}{c}\mathrm{Pu} \\
(\mathrm{kN})\end{array}$ & $\begin{array}{c}\delta u \\
(\mathrm{~mm})\end{array}$ & & & \\
\hline \multirow[t]{2}{*}{ JBC1 (Steel) } & EXP & 51.3 & 12 & 61.5 & 72 & 61.5 & 72 & 26.7 & 1.12 & 1.067 \\
\hline & Vec2 & 56.2 & 12.8 & 61.2 & 72 & 61.2 & 72 & 29.8 & & \\
\hline \multirow[t]{2}{*}{ JBC2 (SMA and Steel) } & EXP & - & - & 64 & 72 & 64 & 72 & 16.3 & 0.9 & - \\
\hline & Vec2 & 42.7 & 18 & 66.2 & 72 & 66.2 & 72 & 14.9 & & \\
\hline \multirow[t]{2}{*}{ SSB-S-1.0 (Steel) } & EXP & 34 & 11 & 71 & 55 & 71 & 55 & 59 & 1.13 & 0.91 \\
\hline & Vec2 & 44.4 & 10 & 68.4 & 55 & 68.4 & 55 & 67 & & \\
\hline \multirow[t]{2}{*}{ DSB-S-1.0 (Steel) } & EXP & 36 & 14 & 57 & 85 & 57 & 85 & 171.7 & 0.97 & 1.07 \\
\hline & Vec2 & 38 & 15 & 56.4 & 75 & 53.4 & 85 & 166 & & \\
\hline \multirow[t]{2}{*}{ SSB-P-1.0 (SMA and Steel) } & EXP & 47 & 32 & 68 & 75 & 68 & 75 & 26 & 0.81 & 0.94 \\
\hline & Vec2 & 45 & 30 & 65.1 & 67 & 64.2 & 75 & 21 & & \\
\hline \multirow[t]{2}{*}{ DSB-P-1.0 (SMA and Steel) } & EXP & 30 & 39 & 39 & 120 & 39 & 120 & 51.2 & 0.79 & 1 \\
\hline & Vec2 & 38 & 39 & 49 & 120 & 49 & 120 & 40.4 & & \\
\hline
\end{tabular}



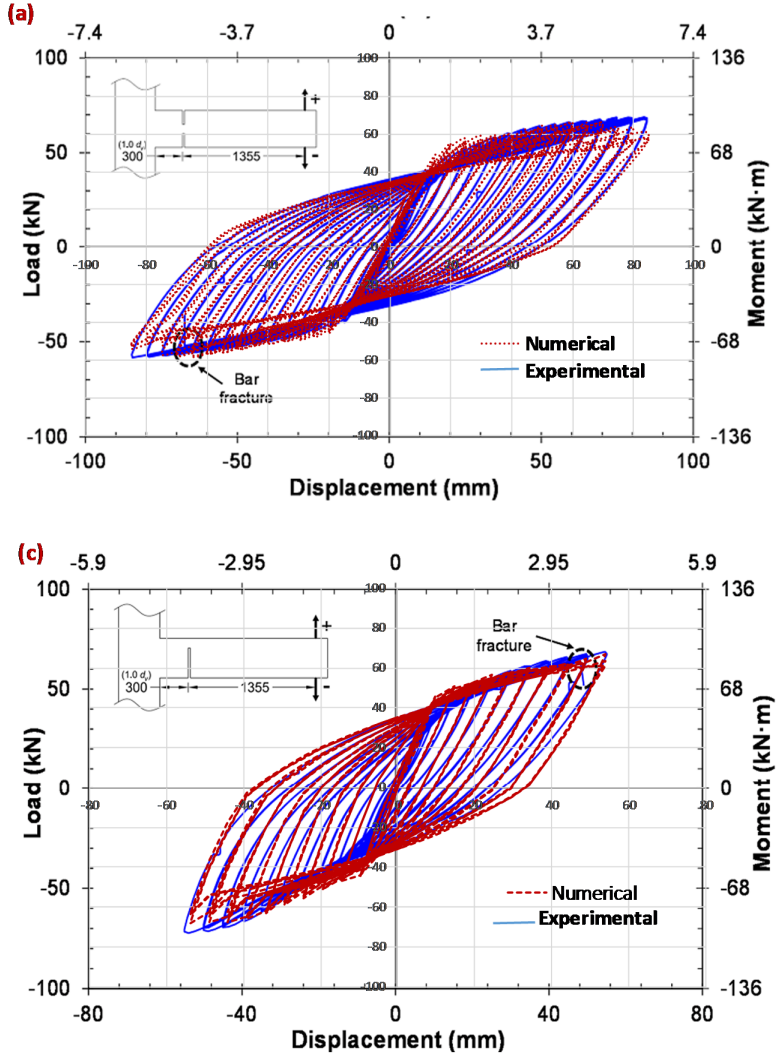
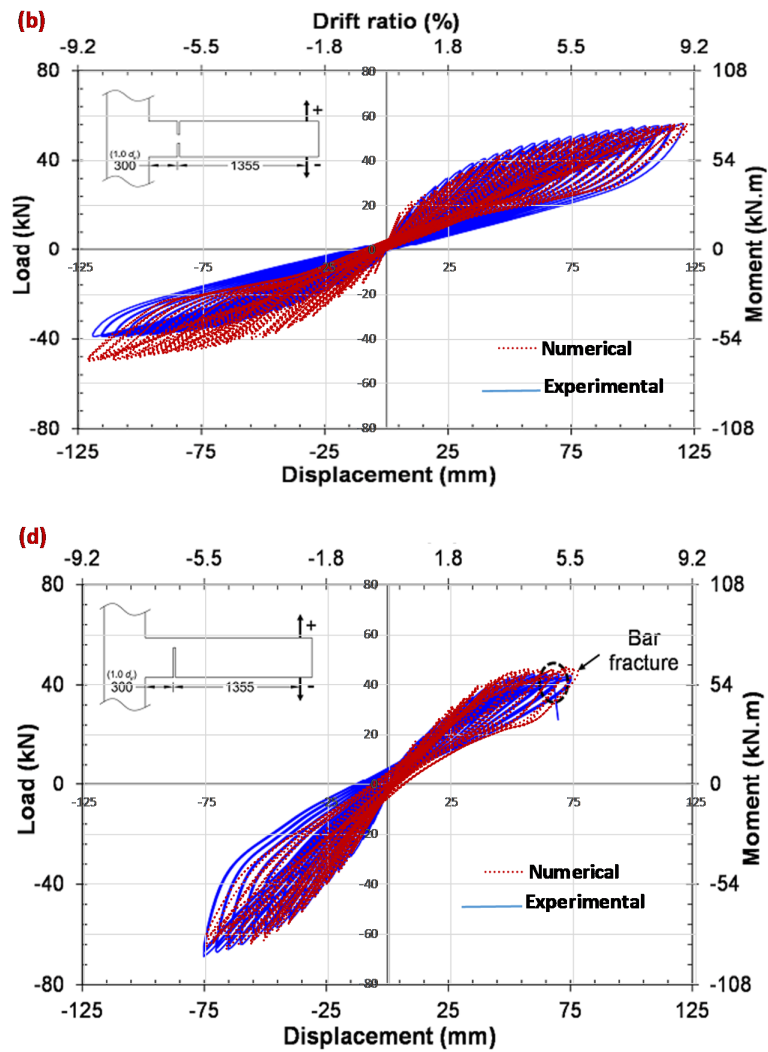

Figure 11: Comparison between the numerical and experimental (Oudah 2015) results of beam tip load-displacement relationship. (a) DSB_S_1.0, (b) DSB_P_1.0, (c) SSB_S_1.0 and (d) SSB_P_1.0.

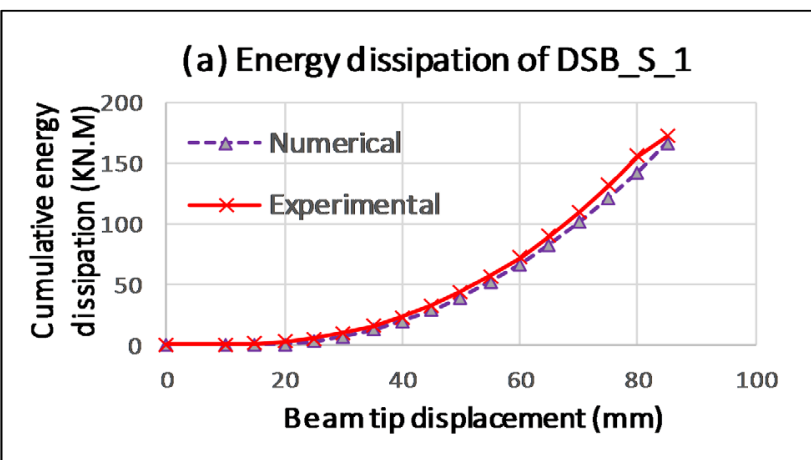

\section{(c) Energy dissipation of SSB_S_1}

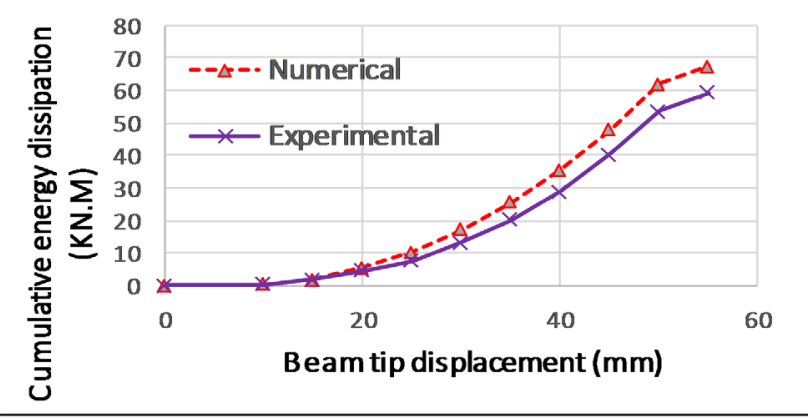

(b) Energy dissipation of DSB_P_1

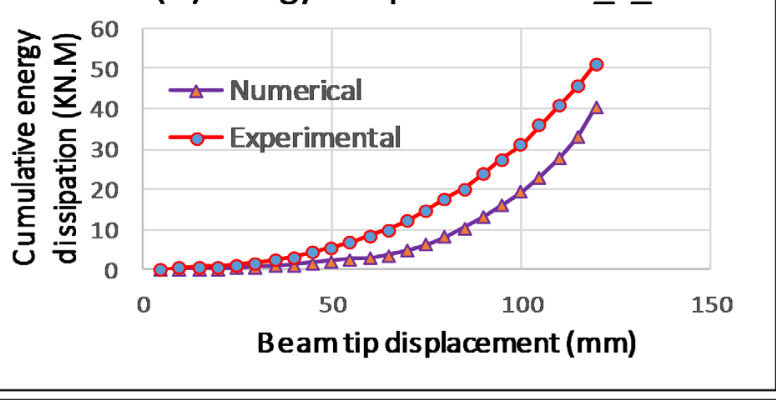

(d) Energy dissipation of SSB_P_1

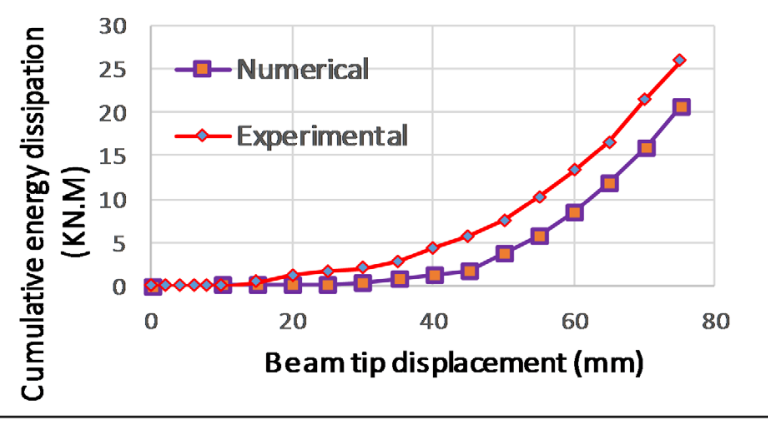

Figure 12: Comparison between the numerical and experimental (Oudah 2015) results of cumulative hysteresis energy dissipation. (a) DSB_S_1.0, (b) DSB_P_1.0, (c) SSB_S_1.0 and (d) SSB_P_1.0. 
Figure 16 illustrates the effect of K2 (post-yield stiffness) on the seismic behavior of JBC2, while K1, K3, and Fy were constant. K2 affected the load-displacement curve at any displacement greater than $20 \mathrm{~mm}$. The load-bearing capacity of JBC2 increased by approximately $53 \%$ as the K2 increased from 0 to $8 \mathrm{GPa}$. While the energy dissipation of JBC2 decreased with increasing $\mathrm{K} 2$.

Vector2 has no option for controlling the parameters affecting the unloading path of the stress-strain curve of SESMA. Therefore, K3 was considered as an alternative for studying the effect of the lower plateau stress factor ( $\beta$ ). The effect of changing K3 on the cyclic response of JBC2 was investigated by using the proposed technique (see Sec. 2.2) and the results are shown in Figure 17. For a better understanding, Figure 17b shows two end half-cycles of the loaddisplacement relationship up to $125 \mathrm{~mm}$. As can be seen in Figure 17b, increasing K3 altered only the unloading path and did not change the envelope curves. Up to $75 \mathrm{~mm}$ displacement, the cumulative energy dissipation decreased by approximately $5 \%$ as $\mathrm{K} 3$ increased from 0 to $3 \mathrm{GPa}$.

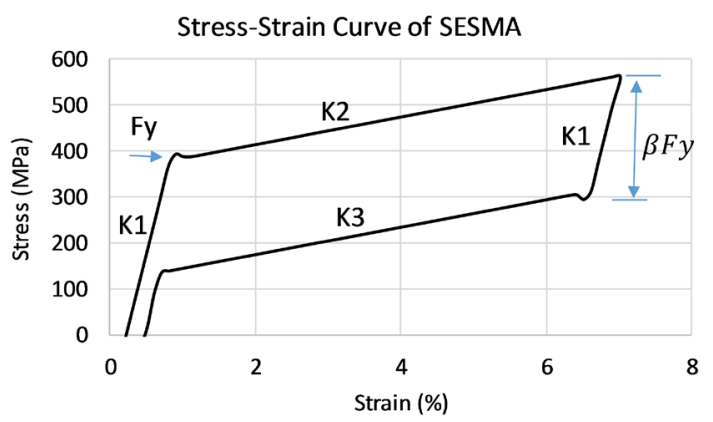

Figure 13: Schematic stress-strain relationship of SESMA

\subsection{Influence of concrete grade}

The influence of the concrete grade (concrete compressive strength) ranging from C30 to C70 on the seismic response of SMA-steel BCJs is illustrated in Figure 18. The change in the concrete grade, experimentally achieved as a result of changing the concrete mixture, can affect other properties of the concrete. In the analysis process by VecTor2, some of these properties can be estimated and updated by the software as a function of the concrete compressive strength if the default value " 0 " is chosen by the user. In the present numerical study, due to the absence of experimental results, the default value was selected for the initial tangent modulus of elasticity, uniaxial tensile strength, strain at the compressive strength, and Poisson's ratio. Furthermore, the maximum bond strength between SMA bars and concrete was changed according to Equation 1 by the user. The bond strength between steel reinforcing bars and concrete was calculated and updated by the software.

As presented in Figure 18, the load bearing capacity and hysteresis energy dissipation of JBC2 respectively increased by $16 \%$ and $29 \%$ as a result of enhancing the concrete grade. It should be mentioned that these variations in the bearing capacity and energy dissipation were due to changing both of the concrete compressive strength and the other associated properties.

\subsection{Influence of beam reinforcement ratio}

Figure 19a shows cyclic and envelope curves of load-displacement responses for different beam reinforcement ratios. As can be seen in Figure 19, an increase in the beam reinforcement ratio led to an increase in the stiffness, strength and energy dissipation of JBC2. The ultimate strength and energy dissipation increased by approximately $75 \%$ and $35 \%$ as the beam reinforcement ratio changed from $1 \%$ to $2 \%$, respectively. 

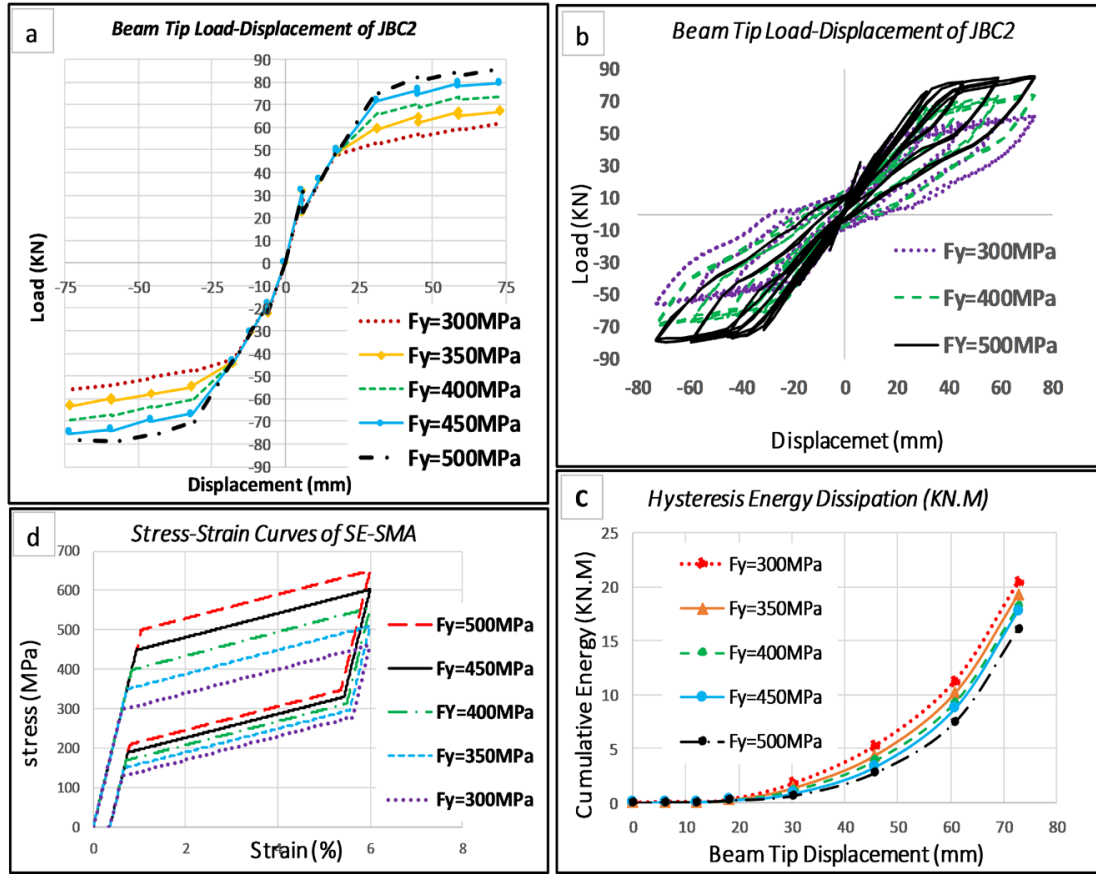

Figure 14: Effect of the Austenite yield strength (Fy) of SESMA rebars on seismic behavior of JBC2: (a) envelopes of the load-displacement curves, (b) hysteresis curves of load-displacement, (c) cumulative energy dissipation, (d) stress-strain curves of SESMA for different values of Fy.

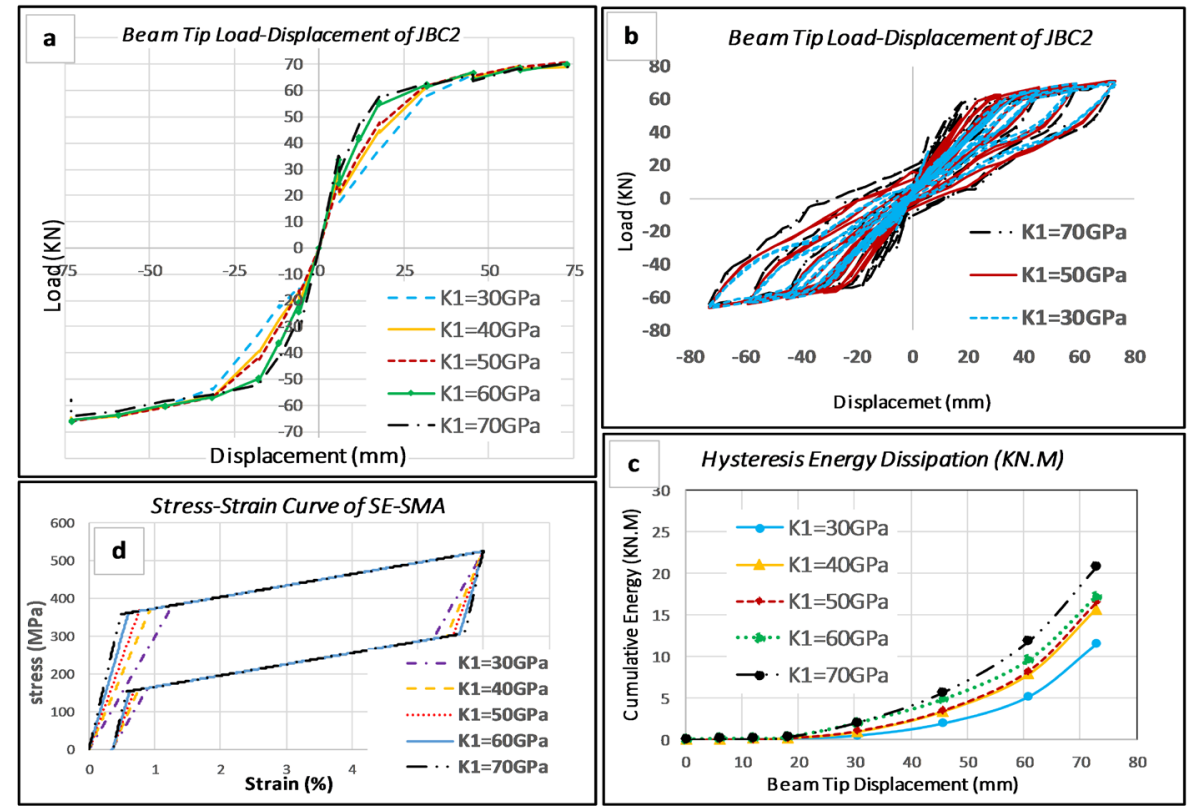

Figure 15: Effect of the Austenite modulus (K1) of SESMA on seismic behavior of JBC2: (a) envelopes of the load-displacement curves, (b) hysteresis curves of load-displacement, (c) cumulative energy dissipation, (d) stress-strain curves of SESMA for different values of $\mathrm{K} 1$. 


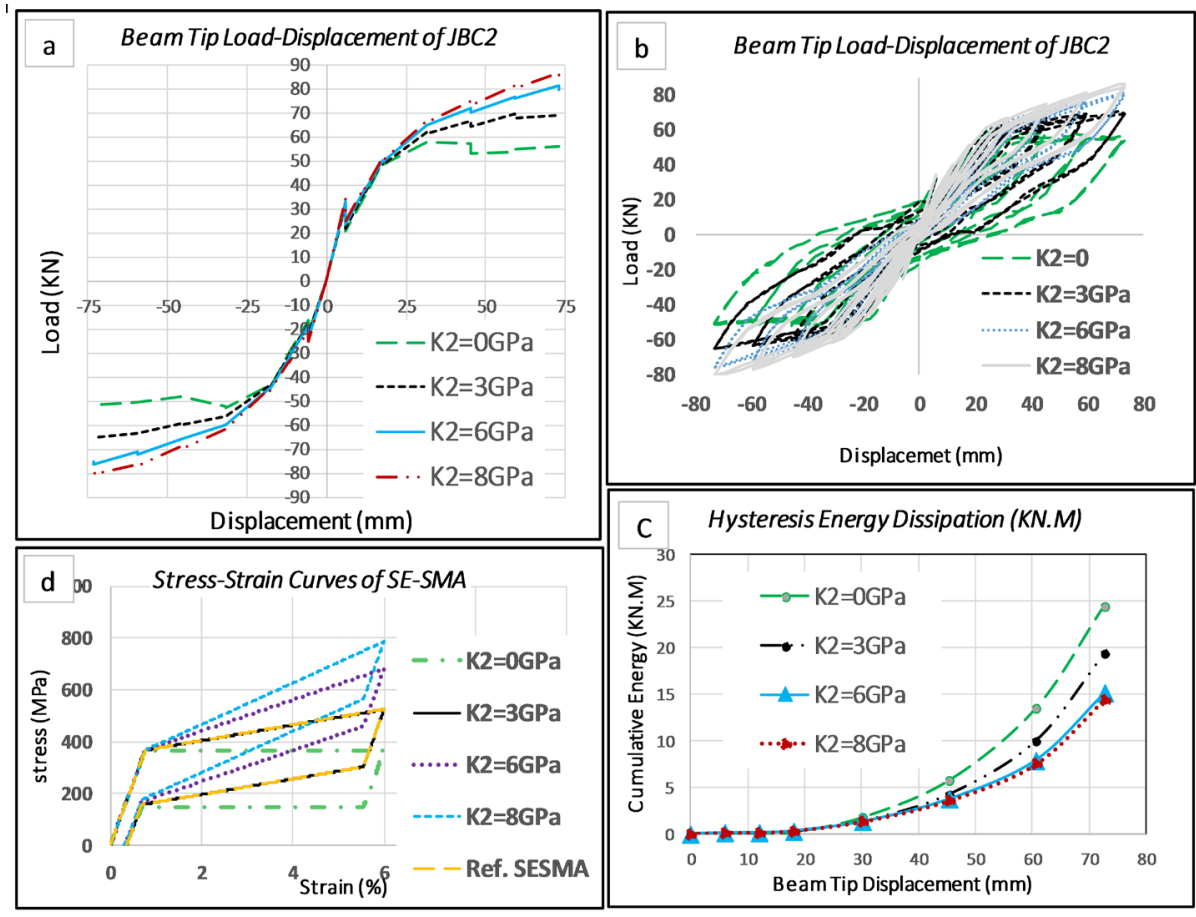

Figure 16: Effect of the post-yield stiffness (K2) of SESMA on seismic behavior of JBC2: (a) envelopes of the load-displacement curves, (b) hysteresis curves of load-displacement, (c) cumulative energy dissipation, (d) stress-strain curves of SESMA for different values of $\mathrm{K} 2$.

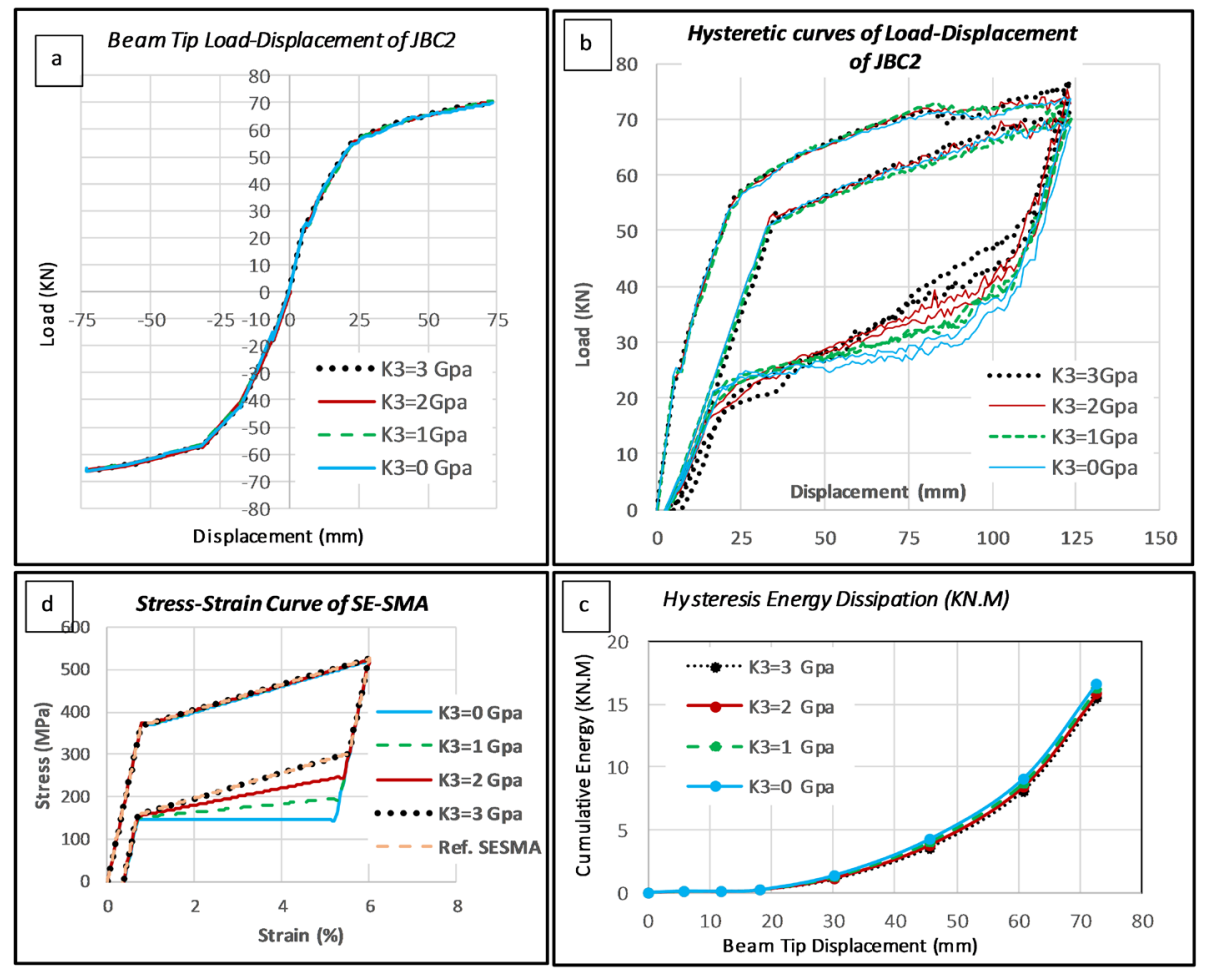

Figure 17: Effect of the lower plateau stress factor (K3) of SESMA on seismic behavior of JBC2: (a) envelopes of the load-displacement curves, (b) two half cycles of the hysteretic load-displacement curves, (c) cumulative energy dissipation, (d) stress-strain curves of SESMA for different values of K3. 


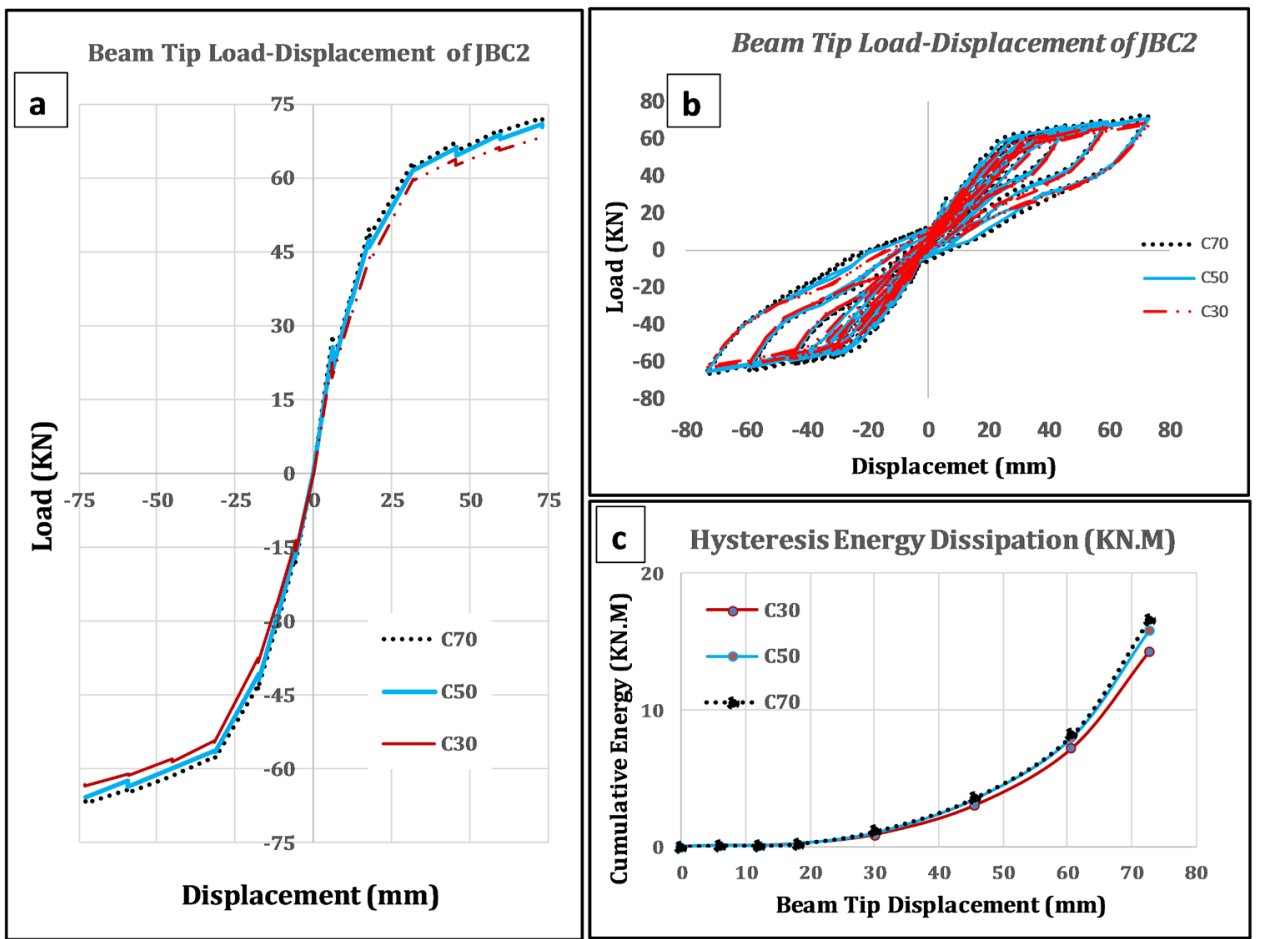

Figure 18: Effect of the concrete strength on seismic behavior of JBC2: (a) envelopes of the load-displacement curves, (b) hysteresis curves of load-displacement, (c) cumulative energy dissipation.

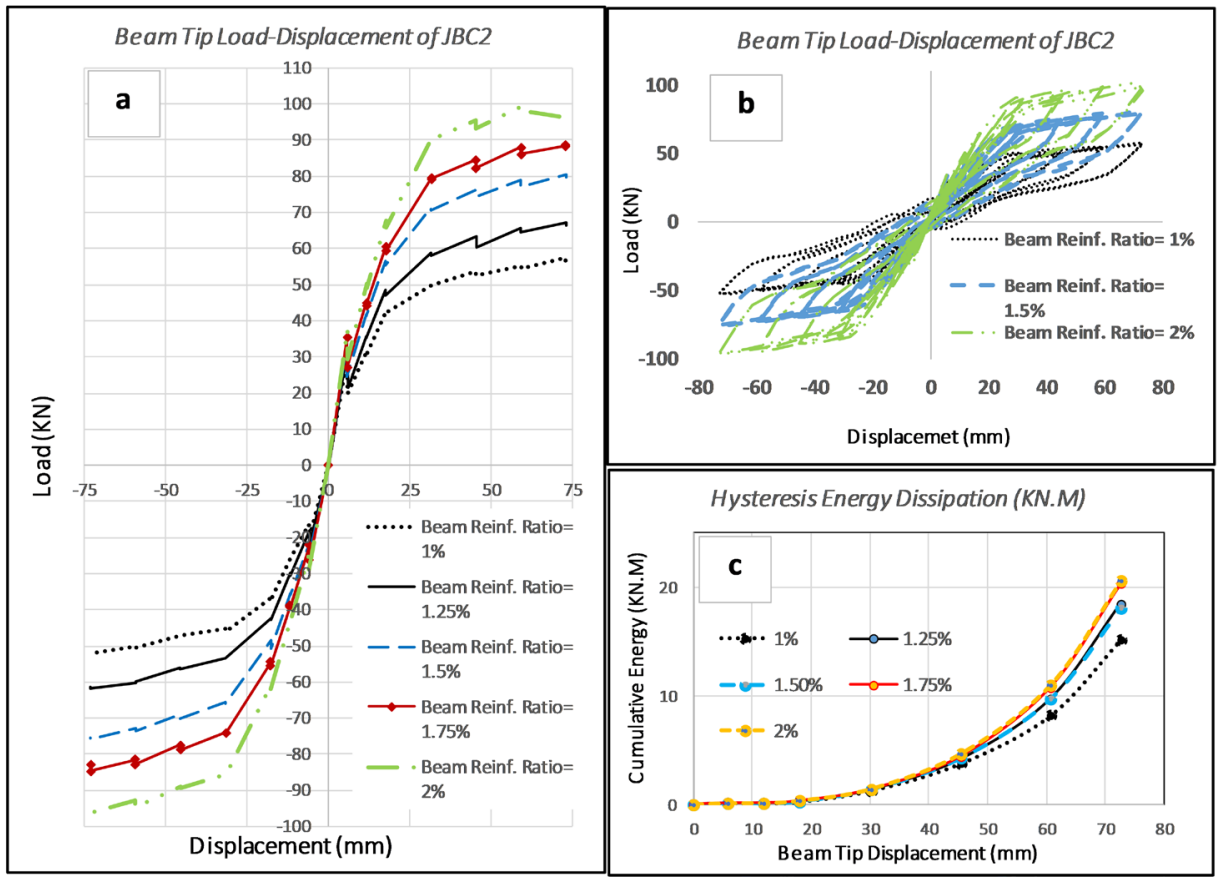

Figure 19: Effect of the beam reinforcement ratio on seismic behavior of JBC2: (an envelope of the load-displacement curves, (b) hysteresis curves of load-displacement, (c) cumulative energy dissipation.

\section{INTRODUCING A COST-EFFECTIVE HYBRID BCJ WITH ENHANCED SEISMIC PERFORMANCE}

Although there is considerable potential for utilizing NiTi bars as reinforcement in concrete structures, the high cost of this material restricts its application in real structures significantly (Youssef et al. 2008). However, according to the best knowledge of us, so far, all the previous experimental and numerical studies associated with SMA-steel RC beamcolumn joints (which were introduced in section 1 and some of them were numerically modeled in subsections 2.3 and 2.4) have focused on replacing flexural steel bars with NiTi in the plastic hinge developed near the column face. 
To reduce the amount of required SESMA and to improve the seismic performance of hybrid SMA-steel RC BCJs, two ideas were proposed and numerically investigated. First, utilizing a different type of SESMA bars with lower fabrication cost and better seismic performance (such as FeNCATB bars) in the plastic hinge zone. Second, employing an improved detailing for relocating the plastic hinge to the other region of the beam with lower moment demand, resulting in decreasing the number and size of the SESMA bars required in the plastic hinge.

Initially, the influence of the type of SESMA on seismic performance of hybrid BCJs was investigated. To this end, the mechanical properties of SESMA bars in the plastic hinge region of the numerical model of JBC2 were replaced with those of three different types of SESMAs extracted from previous studies (see Table 2). The aim was to find a suitable alternative for Ni55Ti45 bars, leading to decreasing the number and size of the required SESMA bars (in the plastic hinge) and enhancing the seismic performance of hybrid SMA-steel BCJs. Figure 20 and Figure 21 compare the numerical responses of JBC2 with different types of SESMAs in terms of various criteria such as cracking pattern, hysteresis energy dissipation, yielding and ultimate strengths, and residual deformation. As can be seen, the greater yield and ultimate stresses of SESMA bars resulted in a greater load-bearing capacity of the SMA-steel BCJ, and increasing Young's modulus of SESMA increased the initial stiffness of the hybrid BCJ.

Among the SESMAs available in Table 2, FeNCATB (Fe-Ni-Co-Al-Ta-B) seems to possess great potential for utilizing as reinforcing bar in RC structures. This alloy is a ferrous polycrystalline SESMA which has a high superelastic range of over $13 \%$ at room temperature (Tanaka et al. 2010). This Fe-based alloy has greater strength and energy dissipation capacity than NiTi which is commercially available. However, as can be seen in Figure 20b and Figure 22a, replacing $2 \# 20$ $\mathrm{mm}$ Ni55Ti45 bars with 2\#20 mm FeNCATB bars did not lead to a favorable recentering that can be attributed to the greater yield and ultimate strengths of FeNCATB in comparison with NiTi. To achieve suitable recentering, the number and size of FeNCATB bars (in the plastic hinge region) and steel reinforcement (in other places of the BCJ) should be determined in such a way that the yielding occurs in FeNCATB bars, while steel rebars remain in the elastic range. In the following, three different scenarios that can lead to yielding of FeNCATB bars were numerically investigated and their results are illustrated in Figure 22. These scenarios can be summarized as follows:

1. The Use of $2 \# 18 \mathrm{~mm}$ FeNCATB bars at the plastic hinge region and $2 \# 20 \mathrm{~mm}$ steel bars at the other regions of the SMA-steel BCJ model (Figure 22b).

2. The Use of $2 \# 16 \mathrm{~mm}$ FeNCATB bars at the plastic hinge region and $2 \# 20 \mathrm{~mm}$ steel bars at the other regions of the SMA-steel BCJ model (Figure 22c).

3. The Use of $2 \# 20 \mathrm{~mm}$ FeNCATB bars at the plastic hinge region and $2 \# 24 \mathrm{~mm}$ steel bars at the other regions of the SMA-steel BCJ model (Figure 22d).

As shown in Figure 22b, reducing the size of FeNCATB rebars to $2 \# 18 \mathrm{~mm}$ (the first scenario) can improve the recentering capability to some extent. In this case, because of the yielding of both the steel rebars and SMA bars, residual deformation was not completely eliminated. The use of $2 \# 16 \mathrm{~mm}$ FeNCATB bars, as the second scenario, (Figure 22c) led to good recentering because the plastic hinge was formed at the region reinforced with FeNCATB bars, while steel reinforcement remained in the elastic range. Because of the higher mechanical properties of FeNCATB in comparison with $\mathrm{NiTi}$, the load-bearing capacity of JBC2 with $2 \# 16 \mathrm{~mm}$ FeNCATB bars was comparable with that of JBC2 with $2 \# 20$ $\mathrm{mm}$ Ni55Ti45 bars (see Figure 22c). Furthermore, due to the lower Young's modulus of FeNCATB, as compared to Ni55$\mathrm{Ti} 45$, the initial stiffness of JBC2-FeNcATB was lower than that of JBC2-Ni55Ti45. The result of third scenario (i.e. replacing $2 \# 20 \mathrm{~mm}$ Ni55Ti45 bars by $2 \# 20 \mathrm{~mm}$ FeNCATB bars at the plastic hinge region and increasing the steel bars diameter to $24 \mathrm{~mm}$ at the other regions of the beam) is shown in Figure 22d. In this case, yielding only occurs in FeNCATB bars, and due to the larger diameter of the SESMA bars used as compared to the other cases (see Figure 22b and c), a better recentering and higher strength were observed.

According to the stress-strain curve of FeNCATB, the optimal use of this alloy occurs in large strains. To investigate this issue, the beam tip displacement of JBC2-FeNCATB was increased up to $125 \mathrm{~mm}$. Numerical results are illustrated in Figure 23 indicating that besides greater load-bearing capacity, JBC2-FeNCATB showed a comparable energy dissipation than JBC2-Ni55Ti45 in large displacements. Such large displacements rarely happen in real structures. Therefore, as an effective alternative, plastic hinge relocation technique (PHRT) may be proposed to optimize the use of these alloys. Applying this technique can lead to an increase in the curvature demand and strain of the rebars at the relocated plastic hinge, for a given drift ratio. Furthermore, PHRT can decrease the amount of required SESMA, because by using this technique plastic hinge is relocated to a region with lower moment demand. Also, the use of this technique can increase the stiffness, strength and energy dissipation of hybrid BCJs through employing additional steel rebars instead of highcost SESMA bars. 

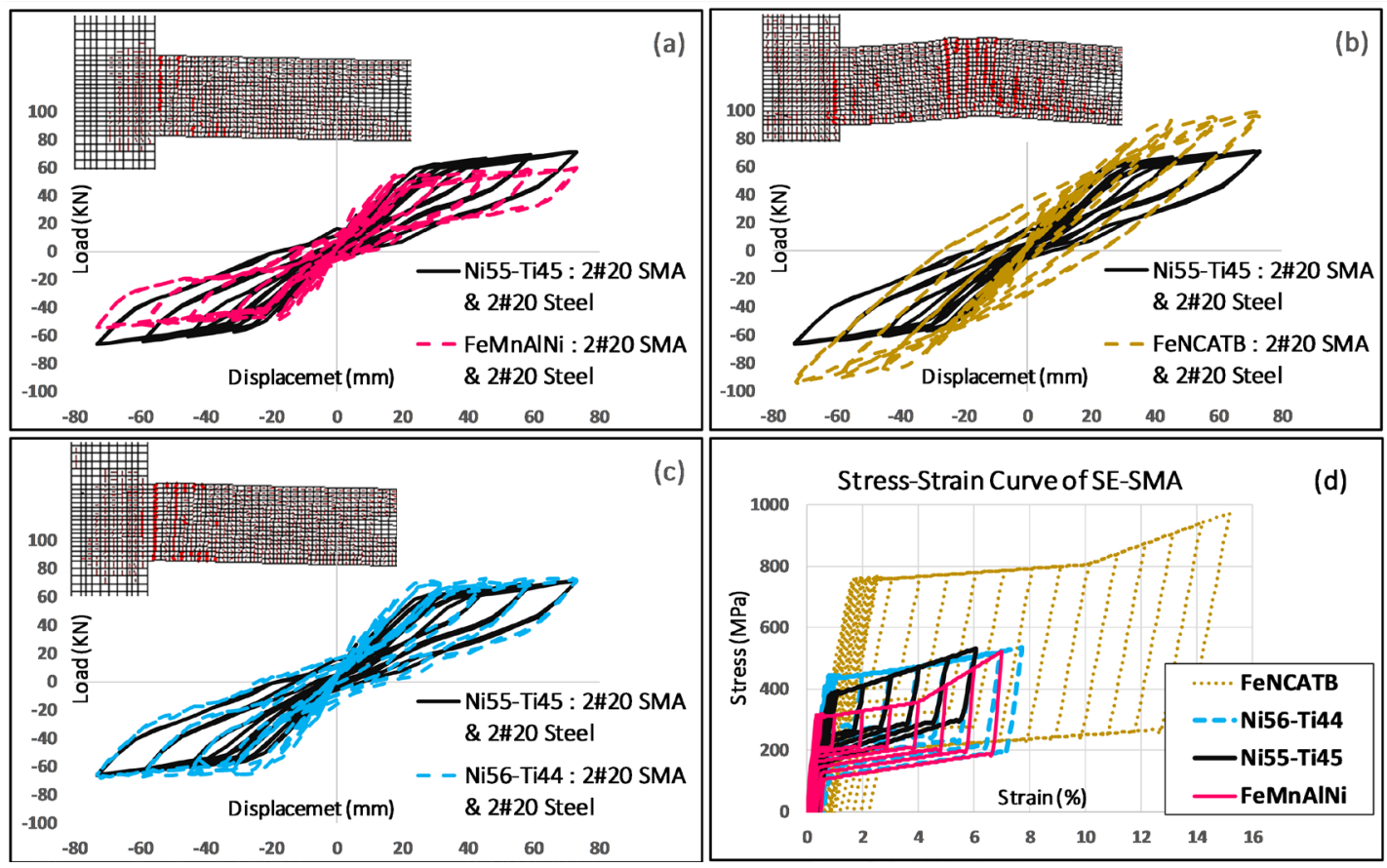

Figure 20: Comparison cyclic response of JBC2-Ni55Ti45 (Youssef et al. 2008) with (a) JBC2-FeMnAINi, (b) JBC2-FeNCATB and (C) JBC2-Ni56Ti44; and (d) Numerical stress-strain curves of the SESMAs.

Figure 24 illustrates the schematic view, cyclic response, and cracking pattern of JBC2-FeNCATB with or without PHRT. As can be seen in Figure 24, the use of PHRT enhanced the seismic performance of JBC2-FeNCATB (in the cases of stiffness, load-bearing capacity, and energy dissipation) even in displacements less than $75 \mathrm{~mm}$. Furthermore, the beamcolumn joint without PHRT requires a greater amount of SMA in the plastic hinge to resist a given moment demand (see Figure 24a and b). As a result, the parallel use of FeNCATB and PHRT can significantly reduce the number and size of the SESMA bars (required at the plastic hinge) and can increase the seismic performance of hybrid SMA-steel BCJs.

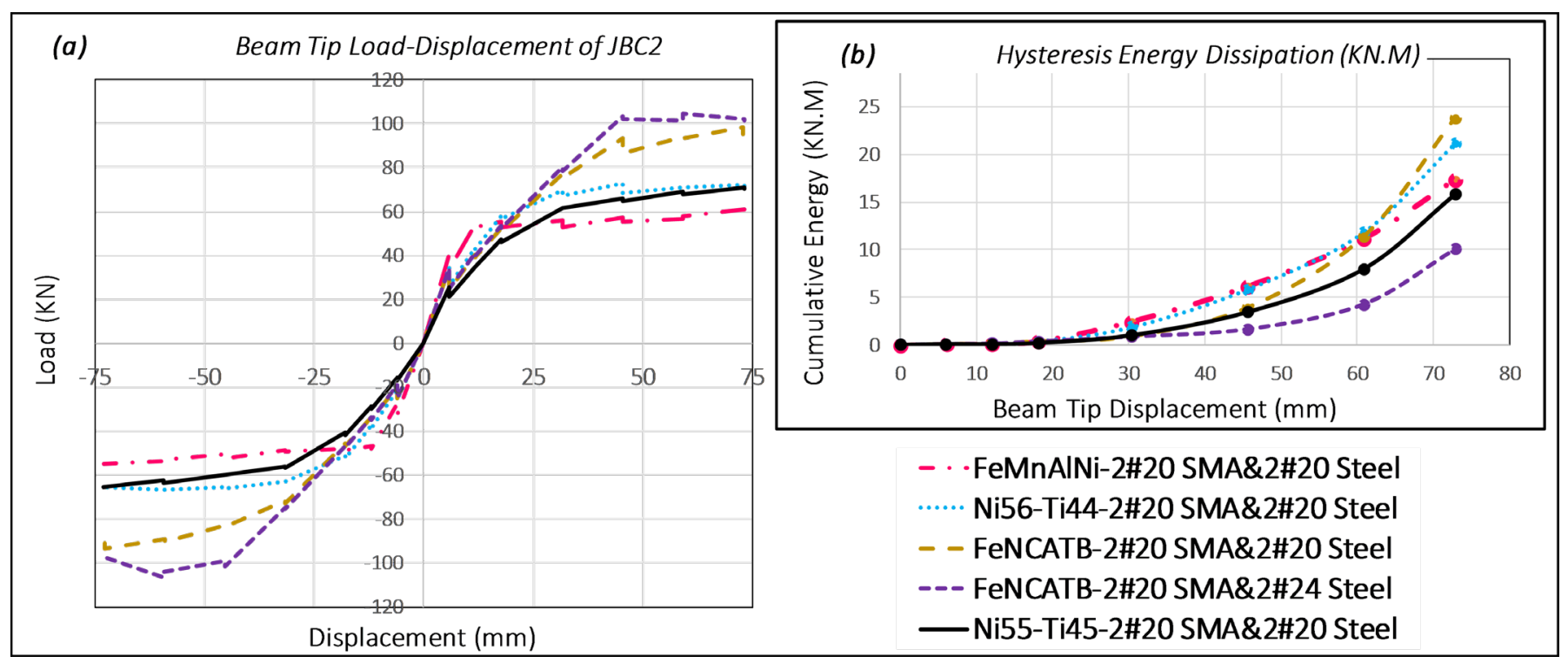

Figure 21: Seismic response of JBC2 reinforced with four different types of SESMAs: (a) envelopes for the load-displacement relationships, (b) cumulative energy dissipation 


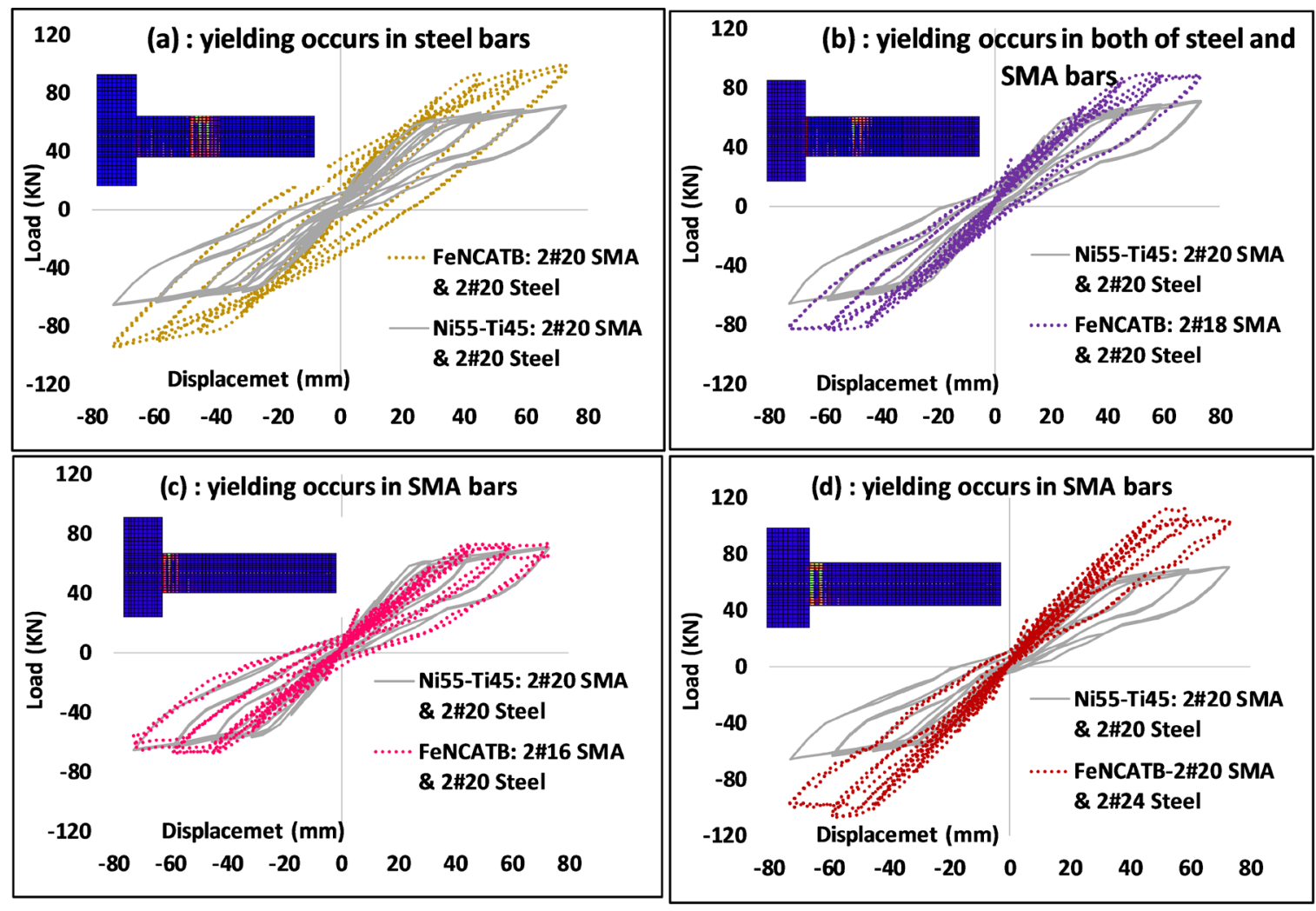

Figure 22: Results of the numerical investigation on JBC2 reinforced with different amounts of FeNCATB-SMA and steel reinforcement.
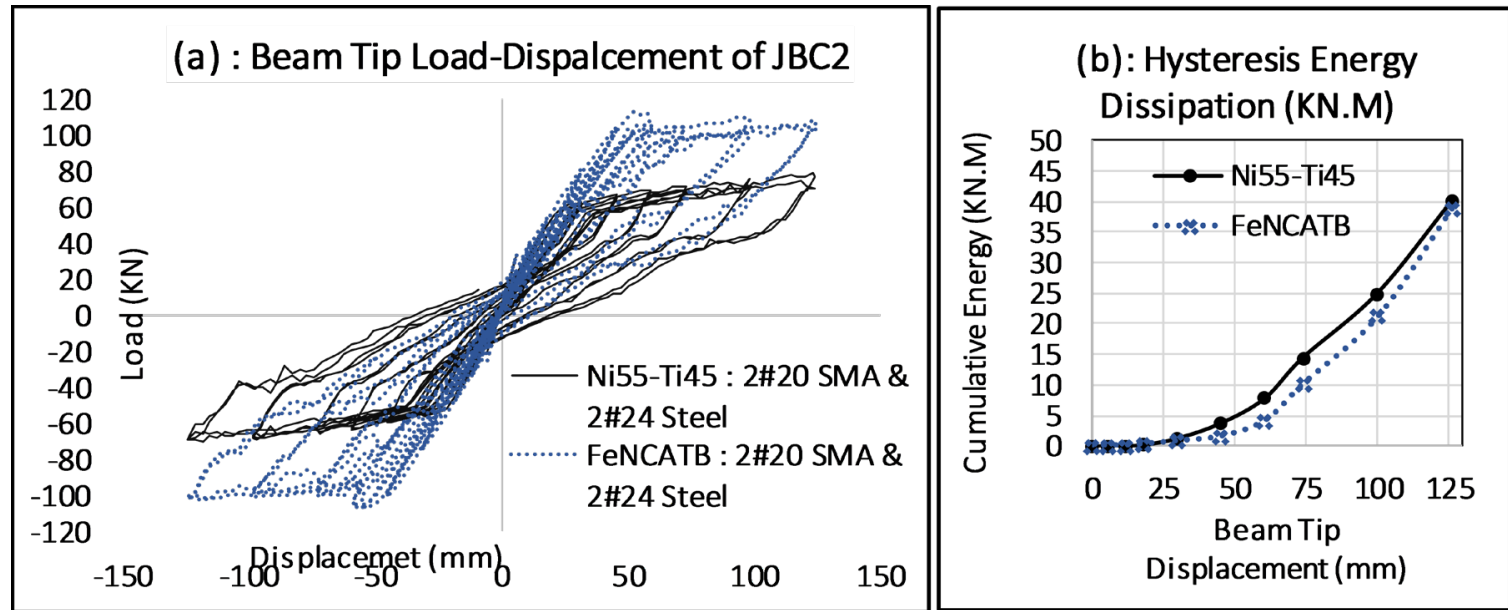

Figure 23: Comparison of (a) cyclic response and (b) hysteresis energy dissipation of JBC2-Ni55Ti45 with JBC2-FeNCATB up to 125 $\mathrm{mm}$ displacement 

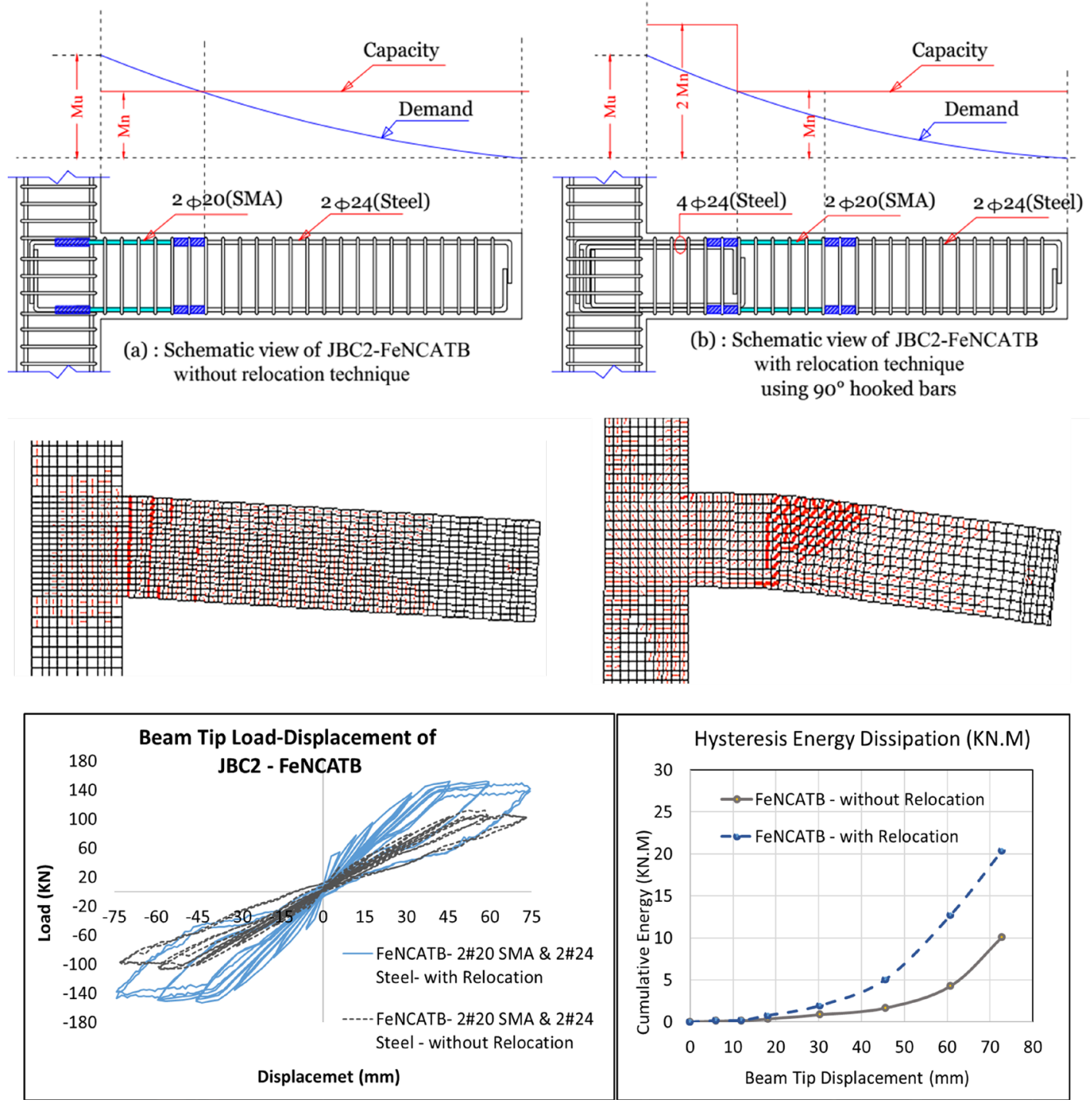

Figure 24: Schematic view, cracking pattern, cyclic response, and energy dissipation of JBC2-FeNCATB with or without PHRT

\section{CONCLUSIONS}

A numerical investigation was carried out to study the effectiveness of nonlinear finite element modeling (by VecTor2) in reproducing the nonlinear cyclic response of self-centering SMA-steel beam-column joints with special detailing. In this regard, a simple and more accurate approach for simulating the cyclic behavior of these BCJs (using VecTor2) was proposed. The proposed model focused on achieving more accurate modeling of bond-slip relationship and stress-strain behavior of SESMA rebars. Comparison between the numerical results and their experimental counterparts reveals that the adopted modeling approach, despite its simplicity, can provide excellent predictions. Furthermore, using the calibrated model, JBC2, a parametric study was performed to evaluate the effect of various design parameters on the nonlinear cyclic response of SESMA-BCJs. Finally, an approach for reducing the amount of required SESMA (at the plastic hinge) and for enhancing the seismic performance of hybrid SMA-steel beam-column joints was proposed and its efficacy was examined.

According to the numerical investigation, the following conclusions can be drawn:

1. The behavior model of the superelastic Shape Memory Alloy adopted by VecTor2 needs to be improved. In some cases, this model is not sufficiently accurate for simulating the unloading path of the stress-strain curve (from the Martensite phase to the Austenite phase) and for predicting the lower plateau stress on this path. Indeed, in this model, the unloading path is estimated by a constant function instead of a linear one. In order to address these shortcomings, in the current study, the superelastic behavior of SMA reinforcing bars was modeled by a modified 
SMA model. This model consists of the parallel use of a linear elastic approach added by SMA2 model available in VecTor2.

2. To obtain a more accurate result, an appropriate user-defined bond stress-slip relationship is required for the sand coated SESMA bars. In the present study, a relationship derived from the previous tests (see Figure 3 ) was examined and a good result was gained.

3. The effects of mechanical properties of SESMA rebars (see Figure 13) on the seismic behavior of the SESMA-BCJs can be summarized as follows: increasing Fy and K2 increases load-bearing capacity and decreases energy dissipation capacity. Initial stiffness and energy dissipation increase with increasing K1 and K2. Increasing K3 decreases energy dissipation.

4. To reduce the amount of required SESMA at the plastic hinge and to enhance the seismic performance of hybrid SMA-steel RCBCJs, two ideas were introduced and their effectiveness was confirmed by the numerical investigation. (a) Utilizing FeNCATB bars which have lower fabrication cost and greater seismic characteristics than commercially available NiTi, in the plastic hinge zone. (b) Relocating the plastic hinge to the other region of the beam with lower moment demand, resulting in decreasing the amount of the required SESMA. This technique also makes optimal use of the SESMA's capacity and increases the stiffness, strength, and energy dissipation of SMA-steel BCJs through employing additional steel rebars instead of high-cost SESMA bars (see Figure 24).

\section{Acknowledgements}

The authors appreciatively acknowledge the financial support provided for this research by K. N. Toosi University of Technology of Iran.

Author Contributions: Investigation, MS Ketabi; Writing-Original Draft, MS Ketabi; Writing-Review \& Editing, M Rezvanisharif and MS Ketabi; Supervision, M Rezvanisharif.

Editor: Marco L. Bittencourt.

\section{References}

Abdelwahed, B. S., Belkassem, B., and Vantomme, J. (2018). Reinforced concrete beam-column inverted knee joint behaviour after ground corner column loss-numerical analysis, Latin American Journal of Solids and Structures 15(10): 1-15.

Abdulridha, A., and Palermo, D. (2017). Behaviour and modelling of hybrid SMA-steel reinforced concrete slender shear wall, Engineering Structures 147: 77-89.

Abdulridha, A., Palermo, D., Foo, S., and Vecchio, F. J. (2013). Behavior and modeling of superelastic shape memory alloy reinforced concrete beams, Engineering Structures 49: 893-904.

Alam, M. S., Moni, M., and Tesfamariam, S. (2012). Seismic overstrength and ductility of concrete buildings reinforced with superelastic shape memory alloy rebar, Engineering Structures 34: 8-20.

Alam, M. S., Youssef, M. a., and Nehdi, M. (2008). Analytical prediction of the seismic behaviour of superelastic shape memory alloy reinforced concrete elements, Engineering Structures 30(12): 3399-3411.

Alam, M. S., Youssef, M. A., and Nehdi, M. (2007). Seismic behaviour of concrete beam-column joints reinforced with superelastic shape memory alloys, 9th Canadian Conf. on Earthquake Engineering, June, Canada.

Asazu, N., Unjoh, S., Hoshikuma, J., and Kondoh, M. (2001). Plastic hinge length of reinforced concrete columns based on the buckling characteristics of longitudinal reinforcement, Doboku Gakkai Ronbunshu, Japan Society of Civil Engineers 2001(682): 177-194.

Azimi, M., Adnan, A. Bin, Tahir, M. M., Sam, A. R. B. M., and Razak, S. M. B. S. A. (2015). Seismic performance of ductility classes medium RC beam-column connections with continuous rectangular spiral transverse reinforcements, Latin American Journal of Solids and Structures 12(4): 787-807.

Beydokhty, E. Z., and Shariatmadar, H. (2016). Behavior of damaged exterior RC beam-column joints strengthened by CFRP composites, Latin American journal of solids and structures 13(5): 880-896. 
Billah, A. H. M. M., and Alam, M. S. (2012). Seismic performance of concrete columns reinforced with hybrid shape memory alloy (SMA) and fiber reinforced polymer (FRP) bars, Construction and Building Materials 28(1): 730-742.

Billah, A. H. M. M., and Alam, M. S. (2016). Bond behavior of smooth and sand-coated shape memory alloy (SMA) rebar in concrete, Structures 5: 186-195.

Comité Euro-International du Béton (1993). CEB-FIP model code 1990: Design code. Telford.

Cortés-Puentes, W. L., and Palermo, D. (2017). SMA tension brace for retrofitting concrete shear walls, Engineering Structures 140: 177-188.

Eligehausen, R., Popov, E. P., and Bertero, V. V. (1982). Local bond stress-slip relationships of deformed bars under generalized excitations, http://dx.doi.org/10.18419/opus-415.

Hoshikuma, J., Kawashima, K., Nagaya, K., and Taylor, A. W. (1997). Stress-strain model for confined reinforced concrete in bridge piers, Journal of Structural Engineering 123(5): 624-633.

Jalaeefar, A., and Asgarian, B. (2013). Experimental Investigation of Mechanical Properties of Nitinol, Structural Steel, and Their Hybrid Component, Journal of Materials in Civil Engineering 25(10): 1498-1505.

Janke, L., Czaderski, C., Motavalli, M., and Ruth, J. (2005). Applications of shape memory alloys in civil engineering structuresoverview, limits and new ideas, Materials and Structures 38(5): 578-592.

Kupfer, H., Hilsdorf, H. K., and Rusch, H. (1969). Behavior of concrete under biaxial stresses, Journal Proceedings 66(8): 656666.

Lee, S.-C., Cho, J.-Y., and Vecchio, F. J. (2011). Model for post-yield tension stiffening and rebar rupture in concrete members, Engineering Structures 33(5): 1723-1733.

Montoya, E., Vecchio, F. J., and Sheikh, S. A. (2006). Compression field modeling of confined concrete: constitutive models, Journal of materials in civil engineering 18(4): 510-517.

Najafgholipour, M. A., Dehghan, S. M., Dooshabi, A., and Niroomandi, A. (2017). Finite element analysis of reinforced concrete beam-column connections with governing joint shear failure mode, Latin American Journal of Solids and Structures 14(7): $1200-1225$.

Nehdi, M., Alam, M. S., and Youssef, M. a. (2010). Development of corrosion-free concrete beam-column joint with adequate seismic energy dissipation, Engineering Structures 32(9): 2518-2528.

Omori, T., Ando, K., Okano, M., Xu, X., Tanaka, Y., Ohnuma, I., Kainuma, R., and Ishida, K. (2011). Superelastic effect in polycrystalline ferrous alloys, Science 33(6038): 68-71.

Oudah, F. (2015). Development of innovative self-centering concrete beam-column connections reinforced using shape memory alloys, Ph.D. Thesis, University of Calgary, Canada.

Oudah, F., and El-Hacha, R. (2017). Plastic hinge relocation in concrete structures using the double-slotted-beam system, Bulletin of Earthquake Engineering 15(5): 2173-2199.

Ozbulut, O. E., Hurlebaus, S., and DesRoches, R. (2011). Seismic response control using shape memory alloys: a review, Journal of Intelligent Material Systems and Structures 22(14): 1531-1549.

Palermo, D., and Vecchio, F. J. (2003). Compression field modeling of reinforced concrete subjected to reversed loading: formulation, ACl Structural Journal 100(5): 616-625.

Richart, F. E., Brandtzaeg, A., and Brown, R. L. (1928). A study of the failure of concrete under combined compressive stresses, Technical Report, University of Illinois at Urbana Champaign, College of Engineering, Engineering Experiment Station.

Roh, H., and Reinhorn, A. M. (2010). Hysteretic behavior of precast segmental bridge piers with superelastic shape memory alloy bars, Engineering Structures 32(10): 3394-3403.

Ronagh, H. R., and Baji, H. (2014). On the FE modeling of FRP-retrofitted beam-column subassemblies, International Journal of Concrete Structures and Materials 8(2): 141-155.

Sagbas, G., Vecchio, F. J., and Christopoulos, C. (2011). Computational modeling of the seismic performance of beam-column subassemblies, Journal of earthquake engineering 15(4): 640-663. 
Saiidi, M. S., Brien, M. O., and Sadrossadat-Zadeh, M. (2009). Cyclic response of concrete bridge columns using superelastic nitinol and bendable concrete, ACl Structural Journal 106(1): 69-77.

Saiidi, M. S., Sadrossadat-Zadeh, M., Ayoub, C., and Itani, A. (2007). Pilot study of behavior of concrete beams reinforced with shape memory alloys, Journal of materials in civil engineering 19(6): 454-461.

Saiidi, M. S., and Wang, H. (2006). Exploratory study of seismic response of concrete columns with shape memory alloys reinforcement, $\mathrm{ACl}$ structural journal 103(3): 435-442.

Sanabria Diaz, R. A., de Oliveira, L. H. B., Trautwein, L. M., de Almeida, L. C., and dos Santos, A. C. (2018). Aspects of finite element modeling of punching shear behavior of reinforced concrete flat slabs, Latin American Journal of Solids and Structures 15(10): 1-22.

Seckin, M. (1982). Hysteretic behaviour of cast-in-place exterior beam column sub-assemblies, Ph.D. Thesis, University of Toronto, Canada.

Song, G., Ma, N., and Li, H.-N. (2006). Applications of shape memory alloys in civil structures, Engineering Structures 28(9): 1266-1274.

Tanaka, Y., Himuro, Y., Kainuma, R., Sutou, Y., Omori, T., and Ishida, K. (2010). Ferrous polycrystalline shape-memory alloy showing huge superelasticity, Science 327(5972): 1488-1490.

Tassios, T. P., and Vintzēleou, E. N. (1987). Concrete-to-concrete friction, Journal of Structural Engineering 113(4): 832-849.

Tazarv, M., and Saiidi, M. (2014). Reinforcing NiTi superelastic SMA for concrete structures, Journal of Structural Engineering 141(8): 401-419.

Del Vecchio, C., Kwon, O., Di Sarno, L., and Prota, A. (2015). Accuracy of nonlinear static procedures for the seismic assessment of shear critical structures, Earthquake Engineering \& Structural Dynamics 44(10): 1581-1600.

Del Vecchio, C., Di Ludovico, M., Prota, A., and Manfredi, G. (2016). Modelling beam-column joints and FRP strengthening in the seismic performance assessment of RC existing frames, Composite Structures 142: 107-116.

Vecchio, F. J. (2000). Disturbed stress field model for reinforced concrete: formulation, Journal of structural engineering 126(9): 1070-1077.

Vecchio, F. J., and Collins, M. P. (1986). The modified compression-field theory for reinforced concrete elements subjected to shear, ACl J. 83(2): 219-231.

Vecchio, F. J., and Lai, D. (2004). Crack shear-slip in reinforced concrete elements, Journal of Advanced Concrete Technology 2(3): 289-300.

Verderame, G. M., De Carlo, G., Ricci, P., and Fabbrocino, G. (2009). Cyclic bond behaviour of plain bars. Part II: Analytical investigation, Construction and building Materials 23(12): 3512-3522.

Wierschem, N., and Andrawes, B. (2010). Superelastic SMA-FRP composite reinforcement for concrete structures, Smart Materials and Structures 19(2), 1-13.

Wong, P. S., Vecchio, F. J., and Trommels, H. (2013). Vector2 \& Formworks user's manual second edition, University of Toronto, Canada.

Youssef, M. A., Alam, M. S., and Nehdi, M. (2008). Experimental investigation on the seismic behavior of beam-column joints reinforced with superelastic shape memory alloys, Journal of Earthquake Engineering 12(7): 1205-1222.

Zafar, A., and Andrawes, B. (2012). Incremental dynamic analysis of concrete moment resisting frames reinforced with shape memory composite bars, Smart Materials and Structures 21(2), 1-14.

Zafar, A., and Andrawes, B. (2015). Seismic behavior of SMA-FRP reinforced concrete frames under sequential seismic hazard, Engineering Structures 98: 163-173. 